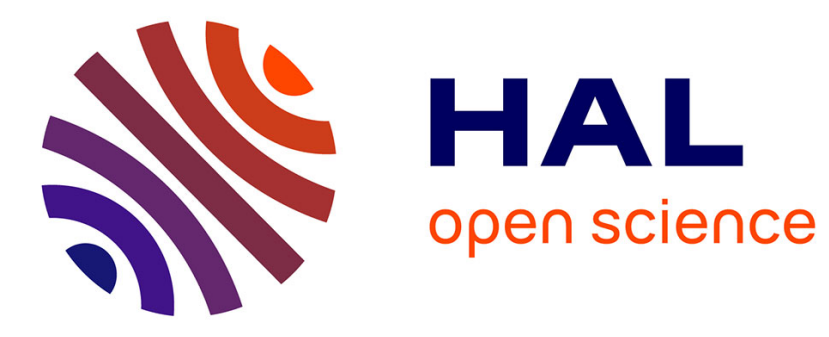

\title{
The spiral troughs of Mars as cyclic steps
}

Isaac B. Smith, John W. Holt, Aymeric Spiga, Alan D. Howard, Gary Parker

\section{To cite this version:}

Isaac B. Smith, John W. Holt, Aymeric Spiga, Alan D. Howard, Gary Parker. The spiral troughs of Mars as cyclic steps. Journal of Geophysical Research. Planets, 2013, 118 (9), pp.1835-1857.

10.1002/jgre.20142 . hal-01107203

\section{HAL Id: hal-01107203 \\ https://hal.science/hal-01107203}

Submitted on 4 Jan 2022

HAL is a multi-disciplinary open access archive for the deposit and dissemination of scientific research documents, whether they are published or not. The documents may come from teaching and research institutions in France or abroad, or from public or private research centers.

Copyright

L'archive ouverte pluridisciplinaire HAL, est destinée au dépôt et à la diffusion de documents scientifiques de niveau recherche, publiés ou non, émanant des établissements d'enseignement et de recherche français ou étrangers, des laboratoires publics ou privés. 


\title{
The spiral troughs of Mars as cyclic steps
}

\author{
Isaac B. Smith, ${ }^{1}$ John W. Holt, ${ }^{1}$ Aymeric Spiga, ${ }^{2}$ Alan D. Howard, ${ }^{3}$ and Gary Parker ${ }^{4}$ \\ Received 10 January 2013; revised 11 August 2013; accepted 15 August 2013; published 18 September 2013.
}

[1] We combine observations of stratigraphy, morphology, and atmospheric processes to relate the spiral troughs on Mars' polar layered deposits to a class of features known as cyclic steps. Cyclic steps are quasi-stable, repeating, and upstream-migrating bed forms that have been studied in terrestrial and submarine environments. The repeating pattern is bounded by hydraulic jumps, which act to stabilize the form. We use radar stratigraphy from the Shallow Radar instrument on Mars Reconnaissance Orbiter to examine trough evolution and constrain lateral transport. We examine visible images from the Thermal Emission Imaging System and observe low-altitude clouds that we interpret to be the result of katabatic jumps, i.e., the Aeolian counterpart of hydraulic jumps in open channel flow. We then devise a theoretical framework for understanding the origin of the spiral troughs that agree with 10 criteria that should be explained for any scenario to satisfactorily model the spiral troughs. Finally, we use Froude and geometrical analysis to estimate the rate of upstream migration caused by katabatic winds for the spiral troughs.

Citation: Smith, I. B., J. W. Holt, A. Spiga, A. D. Howard, and G. Parker (2013), The spiral troughs of Mars as cyclic steps, J. Geophys. Res. Planets, 118, 1835-1857, doi:10.1002/jgre.20142.

\section{Introduction}

[2] It has long been recognized that north polar layered deposits of Mars are fundamental to our understanding of atmospheric deposition and thus climatic processes there [Cutts et al., 1976; Cutts and Lewis, 1982; Milkovich and Head, 2005; Fishbaugh and Hvidberg, 2006; Hvidberg et al., 2012]. Until recently, investigations have focused on outcrops of exposed layers within the spiral troughs that cover the ice cap surface [Squyres, 1979; Howard et al., 1982; Milkovich and Head, 2005; Fishbaugh et al., 2010]. However, the troughs are modified by wind, which affects the pattern of layer deposition [Howard et al., 1982; Howard, 2000; $\mathrm{Ng}$ and Zuber, 2006; Warner and Farmer, 2008]. Thus, the outcrop record is not a straightforward exposure resulting from horizontal deposition. Instead, the layers must be interpreted in the context of local processes affected by preexisting morphology.

[3] The spiral troughs found on the north and south polar layered deposits of Mars (NPLD and SPLD, respectively) have been the source of much debate since their discovery during the Mariner 9 mission [Murray et al., 1972]. During the following four decades, many distinct hypotheses were developed for the formation of the spiral troughs [Weijermars,

\footnotetext{
${ }^{1}$ Institute for Geophysics, University of Texas, Austin, Texas, USA.

${ }^{2}$ Laboratoire de Météorologie Dynamique, Université Pierre et Marie Curie, Paris, France.

${ }^{3}$ Department of Environmental Sciences, University of Virginia, Charlottesville, Virginia, USA.

${ }^{4}$ University of Illinois at Urbana-Champaign, Urbana, Illinois, USA.

Corresponding author: I. B. Smith, Institute for Geophysics, University of Texas, J.J. Pickle Research Campus, Bldg. 196, 10100 Burnet Rd. (R2200), Austin, TX 78758-4445, USA. (isaac@ig.utexas.edu)

C2013. American Geophysical Union. All Rights Reserved. 2169-9097/13/10.1002/jgre.20142
}

1986; Ivanov and Muhleman, 2000; Kolb and Tanaka, 2001; Pelletier, 2004; Ng and Zuber, 2006; Zeng et al., 2008] and for their physical morphology [Squyres, 1979; Fisher, 1993; Howard et al., 1982; Howard, 2000], but no hypothesis successfully combined the observed stratigraphy with a formation mechanism.

[4] Subsurface data from the Shallow Radar (SHARAD) instrument onboard Mars Reconnaissance Orbiter [Seu et al., 2007a] provided a new method to test the varied hypotheses. Analysis of radar reflectors revealed that the troughs are constructional features, having migrated northward during deposition since their onset [Smith and Holt, 2010]. This finding revitalized a hypothesis of trough migration via ice transport by winds [Howard et al., 1982] and led to a better understanding of how the troughs developed. The story, however, remained incomplete.

[5] In this paper list and discuss 10 criteria that should be necessary to explain for a trough formation model to be successful. We then propose a new trough model that addresses trough initiation, migration, and all major physical characteristics of the spiral troughs. In general, the spiral troughs are more clearly expressed on the NPLD than the SPLD, and our observations focus there; however, the 10 criteria and our model apply to both poles. Our model employs constraints derived from remote sensing imagery and processes known to be active at the Martian poles today. In section 3, we describe low-altitude clouds observed above the troughs, and in section 4 , we interpret those clouds as evidence for katabatic jumps. In section 5, we relate the spiral troughs in both hemispheres to a class of morphological features called cyclic steps, which have been studied on earth for decades. The governing fluid dynamics of cyclic steps is well understood, so their existence within the polar ice on Mars provides unique, scientifically useful insights into the development of the ice cap and into Mars' recent climate. In section 6 , we use this new interpretation 


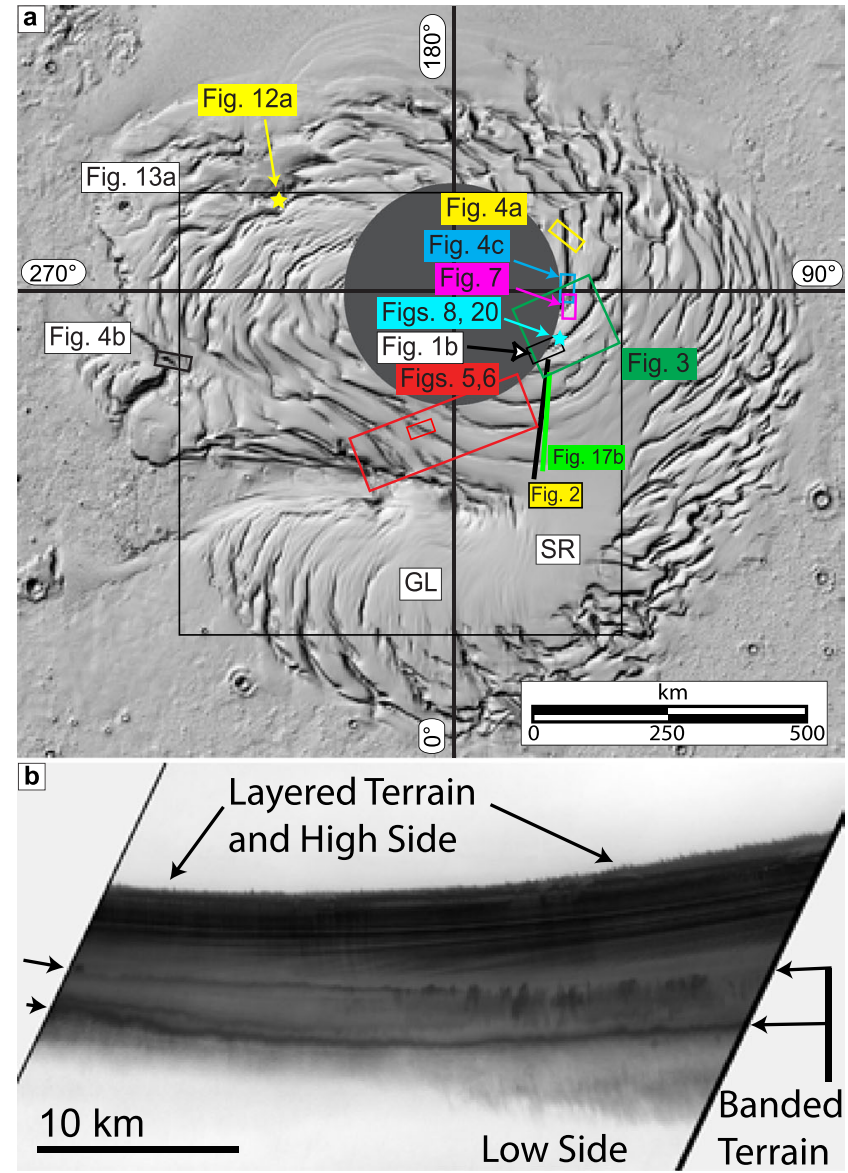

Figure 1. NPLD surface and trough image. (a) Shadedrelief NPLD surface from MOLA elevation data [Smith et al., 2001] showing morphology of troughs and footprint of figures for context. (b) Portion of CTX image P21_009266_2729_XN_87N307W taken during Mars year 29 at $\mathrm{L}_{\mathrm{s}}$ 100.4. Archetypal trough displays low-albedo eroded layers, medium-albedo banded terrain, and highalbedo intertrough regions (top and bottom of image). Exposed layers on trough high side are the results of sublimation and mechanical removal by wind. Banded areas on trough low side exhibit thin feathery deposits that onlap intertrough region.

and 5 years of observations to roughly estimate annual migration rates of NPLD troughs caused by winds. This framework allows us to better characterize atmospheric conditions at the poles of Mars.

\section{Background and Previous Observations}

\subsection{Morphology}

[6] Most spiral troughs on the NPLD conform to a few basic observations. The troughs form an array of clockwisebending depressions bounded by two walls that align subconcentric to the North Pole, offset by $\sim 20^{\circ}$ [Howard, 2000] (Figure 1a). The depressions are on average $\sim 400 \mathrm{~m}$ deep near the pole and reach a maximum depth greater than $1000 \mathrm{~m}$ at the NPLD margin [Pathare and Paige, 2005]. The trough pattern is one of subparallel strike with a characteristic wavelength of between 20 and $70 \mathrm{~km}$, and the lateral extent of a single trough may be from a few to many hundreds of kilometers long [Howard, 1978; Cutts et al., 1979].

[7] Troughs on Gemina Lingula deviate from the subconcentric generalization (Figure 1a). This suggests that a longitudinally uniform process, such as insolation, is not solely responsible for gross trough morphology [Pathare and Paige, 2005]. Because of this variability in orientation, we reference the high and low sides of troughs throughout this paper, rather than equator facing or pole facing (Figures $1 \mathrm{~b}$ and 2a). This reference is determined by elevation and has the benefit of universality across troughs at both poles.

[8] The opposing trough walls are distinct based on albedo, texture, and slope. The high, generally equator-facing, side has the lowest albedo on the NPLD (Figure 1b) [Cutts et al., 1976; $\mathrm{Ng}$ and Zuber, 2006]. It is characterized by layered terrain and a relatively high percentage of dust. Although dust is known to obscure visible layers at the smallest scales, the presence of sharply delineated layers suggests that there is no thick lag obscuring or smoothing the entire surface [Howard, 2000; Herkenhoff et al., 2007; Fishbaugh et al., 2010]. Because of the ablation of volatiles on this surface, the dust originally part of the matrix must be mechanically removed or a lag would obscure the layers. If thick enough, this lag would inhibit further ablation [Howard, 2000; Warner and Farmer, 2008]. The low, generally pole-facing, side of a trough exhibits a

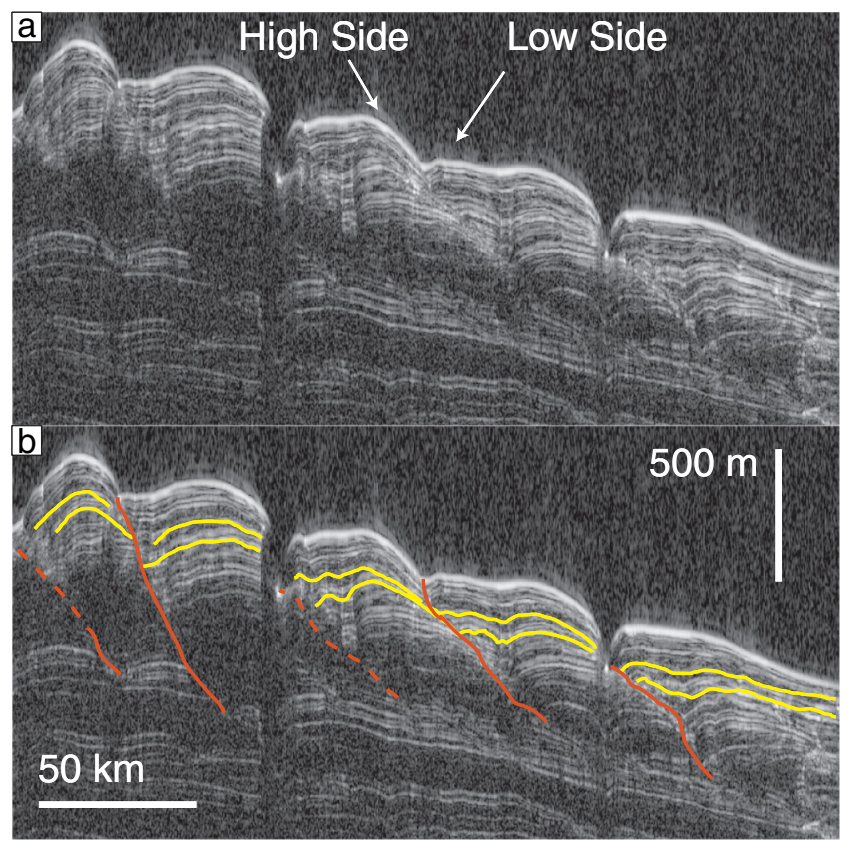

Figure 2. Portion of SHARAD radargram 1294501 crossing spiral troughs. (a) Stratigraphy associated with spiral trough migration is visible beneath the troughs. (b) Same as Figure 2a with interpretation of reflectors to indicate Trough Migration Paths (TMP; orange) and thickness variations between reflectors (yellow) positively correlated across the TMPS (as in Smith and Holt [2010]). Troughs were originally lower and farther south and have risen during accumulation and northward migration. Asymmetric thickness across TMP boundary indicates transport of ice as described in the cyclic step model. Location indicated in Figure 1a. Vertical exaggeration $\sim 80 \times$. 


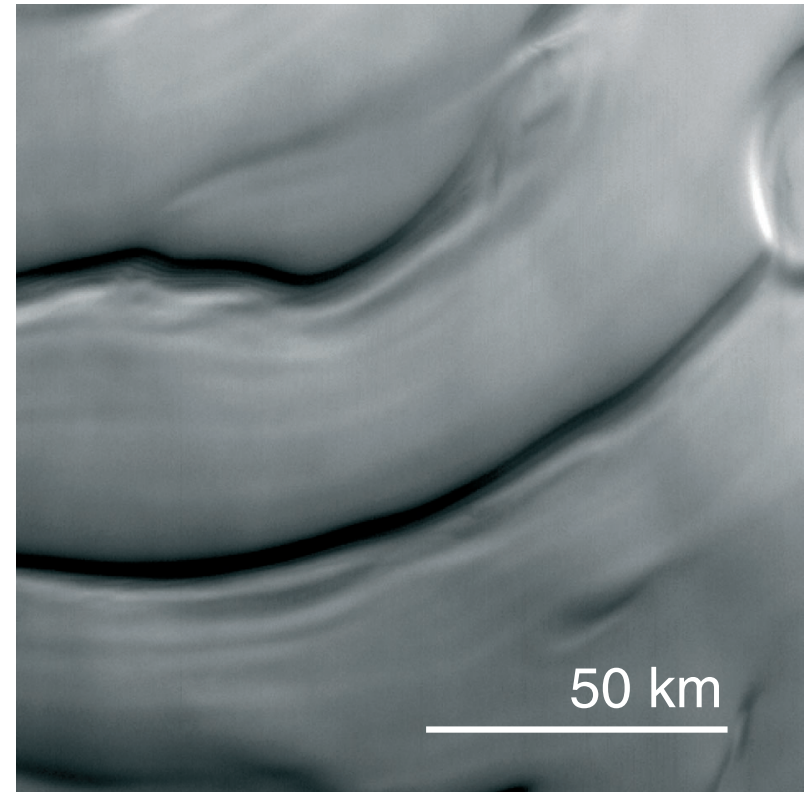

Figure 3. Troughs with undulations. Mars Orbital Camera image M1800805 taken during Mars year 28 at $\mathrm{L}_{\mathrm{s}}$ 35.2. Topographic undulations align roughly parallel to, and on the low side of, NPLD troughs. Locations indicated in Figure 1a.

different morphology, called banded terrain. Banded terrain is considered an irregular mantle that unconformably overlies adjacent terrain and has an albedo intermediate to the layered and intertrough regions [Howard et al., 1982] (Figure 1b).

[9] Besides albedo and texture differences, the trough wall slopes are asymmetric. Slopes range from $2^{\circ}$ to about $15^{\circ}$ on the high side, increasing with distance from the North Pole, while those on the low side are uniformly lower than their counterparts [Pathare and Paige, 2005].

[10] Another feature of the NPLD associated with spiral troughs are smaller-scale, wavelike ridges and swales called "undulations" (Figure 3) [Cutts et al., 1979]. Where exhibited, undulations are found roughly strike parallel and adjacent to the low side of troughs. Their wavelengths are or order 1 to $10 \mathrm{~km}$, and amplitudes range from less than 10 to about $100 \mathrm{~m}$ [Howard, 2000].

\subsection{Radar Stratigraphy}

[11] The advent of SHARAD allowed scientists to test hypotheses of polar layered deposits (PLD) evolution by probing beneath the surface [Seu et al., 2007b; Phillips et al., 2008; Putzig et al., 2009; Holt et al., 2010]. Radar reflectors serve as a proxy for visible stratigraphy and allow for quantitative measurements of subsurface layer geometries [Milkovich et al., 2009; Christian et al., 2013]. Analysis of radar reflectors on the NPLD revealed discontinuities that extend downward from the bottom of the troughs into the ice [Smith and Holt, 2010] (Figure 2). Smith and Holt [2010] interpreted the discontinuities as bounding surfaces that represent trough migration paths (TMPs), indicating the former positions of eroded spiral trough high-side walls.

[12] By mapping the TMPs, it was possible to determine the stratigraphic level at which the spiral troughs formed and thus the amount of accumulation that has occurred since their onset [Smith and Holt, 2010] Smith and Holt [2010] found evidence that the troughs near the NPLD margin at $90^{\circ} \mathrm{E}$ formed stratigraphically higher than the central troughs north of Chasma Boreale, implying that conditions were favorable for NPLD trough formation at least twice. Additionally, the total amount of migration undergone by individual troughs was measured for each region. The oldest troughs, those near Chasma Boreale, have migrated approximately $90-100 \mathrm{~km}$ during $\sim 1000 \mathrm{~m}$ of accumulation, while the younger ones at $90^{\circ} \mathrm{E}$ have migrated between 15 and $25 \mathrm{~km}$ during $\sim 360 \mathrm{~m}$ of accumulation.

[13] Further analysis from SHARAD found that there is a correspondence of reflector separation (layer thickness) with horizontal distance from the TMP [Smith and Holt, 2010]. On the low side, reflector separation increases as it approaches the TMP. In contrast, high-side layers thin as they approach the TMP (Figure 2b). This relationship indicates one of two possibilities: that ice was deposited nonuniformly across a trough [Pathare and Paige, 2005] or ice has been transported from the high side to the low side [Howard et al., 1982; Howard, 2000; Smith and Holt, 2010; in prep]. In either case, the examination of radar reflectors can quantify this asymmetry of net accumulation.

[14] Finally, there are regional differences in TMP slopes and layer thickness variations. Such morphological differences are likely the result of initial conditions such as starting topography and atmospheric state as well as local and regional differences in influencing processes [Smith and Holt, 2011; in prep].

\section{Imagery of Trough Clouds}

\subsection{Observations in the North}

[15] As of this writing, 8105 Thermal Emission Imaging System (THEMIS) images of the north polar region (northward of $82^{\circ}$ ) are available on Arizona State University's Mars Image Explorer for Mars years 26-31 [Christensen et al., 2004]. Several hundred additional images exist from High Resolution Stereo Camera (HRSC) [Neukum and Jaumann, 2004], Mars Orbiter Camera (MOC) [Malin et al., 1998], Context Imager (CTX) [Malin et al., 2007], and the High Resolution Imaging Science Experiment (HiRISE) [McEwen et al., 2007], totaling approximately 8500 optical observations for latitudes greater than $82^{\circ} \mathrm{N}$.

[16] We examined all of the images in the north polar region for evidence of atmosphere-surface interactions. Of those examined, 380 images capture low-altitude clouds with an elongated structure. The earliest clouds each year were observed from $\mathrm{L}_{\mathrm{s}}=24$ to about $\mathrm{L}_{\mathrm{s}}=60$, during Mars' north polar spring (Figure 4a). These early season clouds tend to be wispy and contrast with more opaque, later season clouds. Only a few, $\sim 10$, images of this type of cloud exist. Their origin is unknown but may be related to subliming carbon dioxide frost.

[17] The majority of observed trough clouds occur later in the season and appear to be strongly influenced by NPLD topography, specifically the troughs. We propose to name this type of near-surface cloud "trough clouds." They can be subdivided into two groups: transverse and parallel to the trough strike. Transverse clouds may be found either between or crossing troughs and are only captured in a few images. They orient roughly perpendicular to trough axes (Figure 4b). Parallel clouds, on the other hand, manifest near 


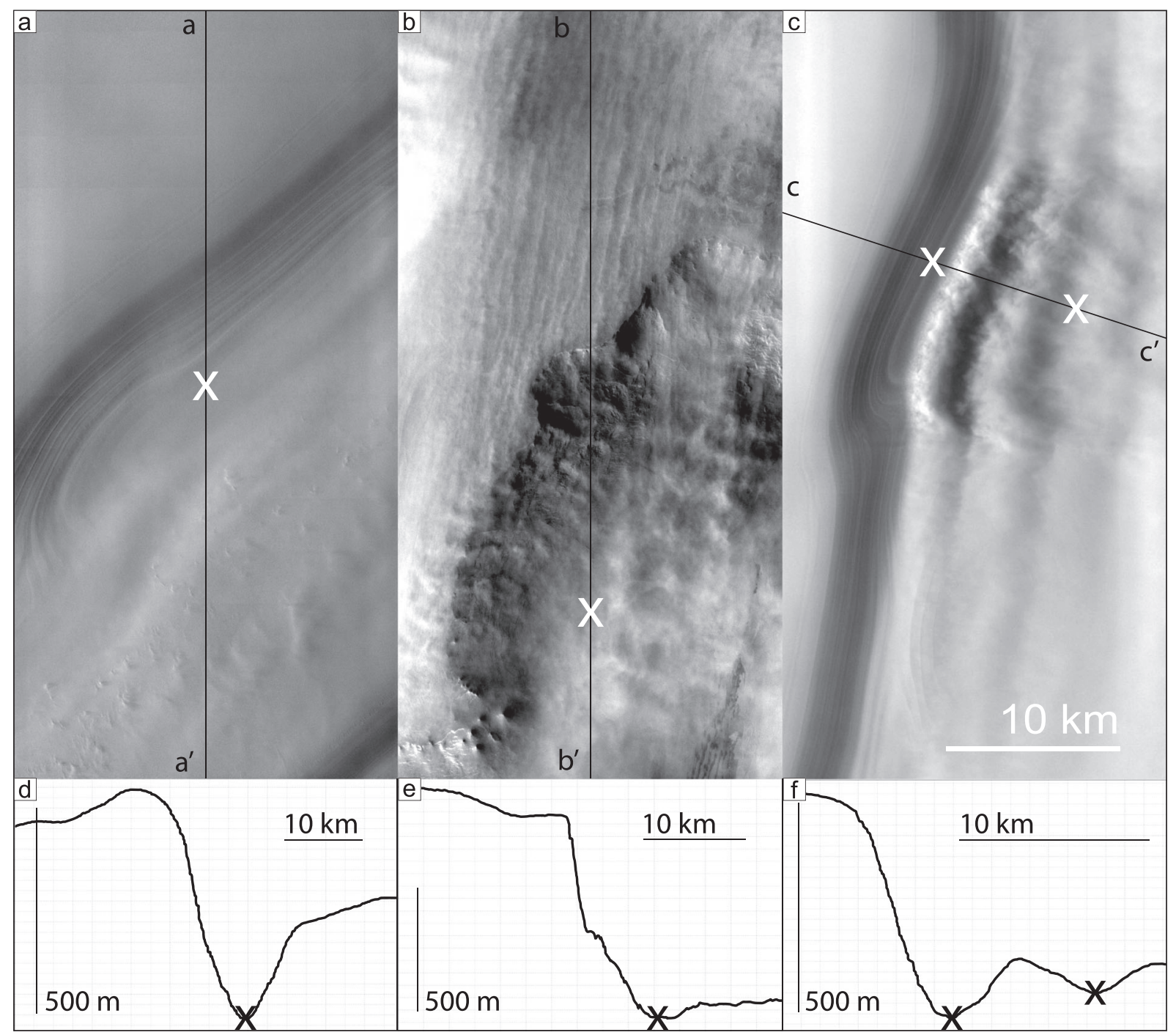

Figure 4. THEMIS VIS images of near-surface ice clouds. (a) V27668015 taken during Mars year 29 at $\mathrm{L}_{\mathrm{s}}$ 43.1, while $\mathrm{CO}_{2}$ ice is still expected on the surface. Wispy clouds suggest sublimation from the surface. Vertical line for MOLA topographic profile in Figure 4d. White X marks lowest elevation of the trough. (b) V37081012 taken during Mars year 30 at $\mathrm{L}_{\mathrm{s}}$ 81.8. Linear clouds flowing downhill, subperpendicular to topography. The clouds interact with the surface, as evidenced by their change in structure across the top of the scarp. Vertical line for MOLA topographic profile in Figure 4e. (c) Portion of V28743004 taken during Mars year 29 at $\mathrm{L}_{\mathrm{s}}$ 82: Trough-parallel clouds form near the bottom of a trough. Katabatic jump is visible at center, near the bottom of the trough. Clouds have undular pattern with a wavelength similar to topographic undulations. Slanted line for MOLA topographic profile in Figure 4f. (d) Topographic profile of vertical line in Figure 4a. (e) Topographic profile of vertical line in Figure 4b. (f) Topographic profile of vertical line in Figure 4c. Black and white Xs mark the local minimum elevations in each trough. Locations shown in Figure 1a.

the bottom and low side of spiral troughs, parallel to their axes (Figures 4c and 5b). To date, trough-parallel clouds are observed in $\sim 350$ THEMIS visible light spectrometer (VIS), one CTX, three MOC, and several HRSC images (Figure 6a) on the NPLD.

[18] Figures 4c, 5b, and 6a share a further commonality besides the trough-parallel clouds. In these images, the parallel clouds exhibit undular or wavelike structures. This morphology is observed in nearly $20 \%$ of images of trough-parallel clouds. The wavelengths of these patterns vary spatially around the NPLD from 1 to $9 \mathrm{~km}$, the majority being 2 to $5 \mathrm{~km}$. This wavelength is smaller than the cross sections of the troughs, which varies between 10 and $25 \mathrm{~km}$.

[19] Transverse linear streaks on the trough high side are also sometimes observed when parallel clouds are present (Figure 7). Linear streaks were previously observed in THEMIS V12432001 [Warner and Farmer, 2008; Smith and Holt, 2010], but only four such images exist, i.e., $\sim 1 \%$ of the total images with trough clouds. Separation of the streaks varies laterally in a single image and ranges from 250 to $500 \mathrm{~m}$ when observed. 


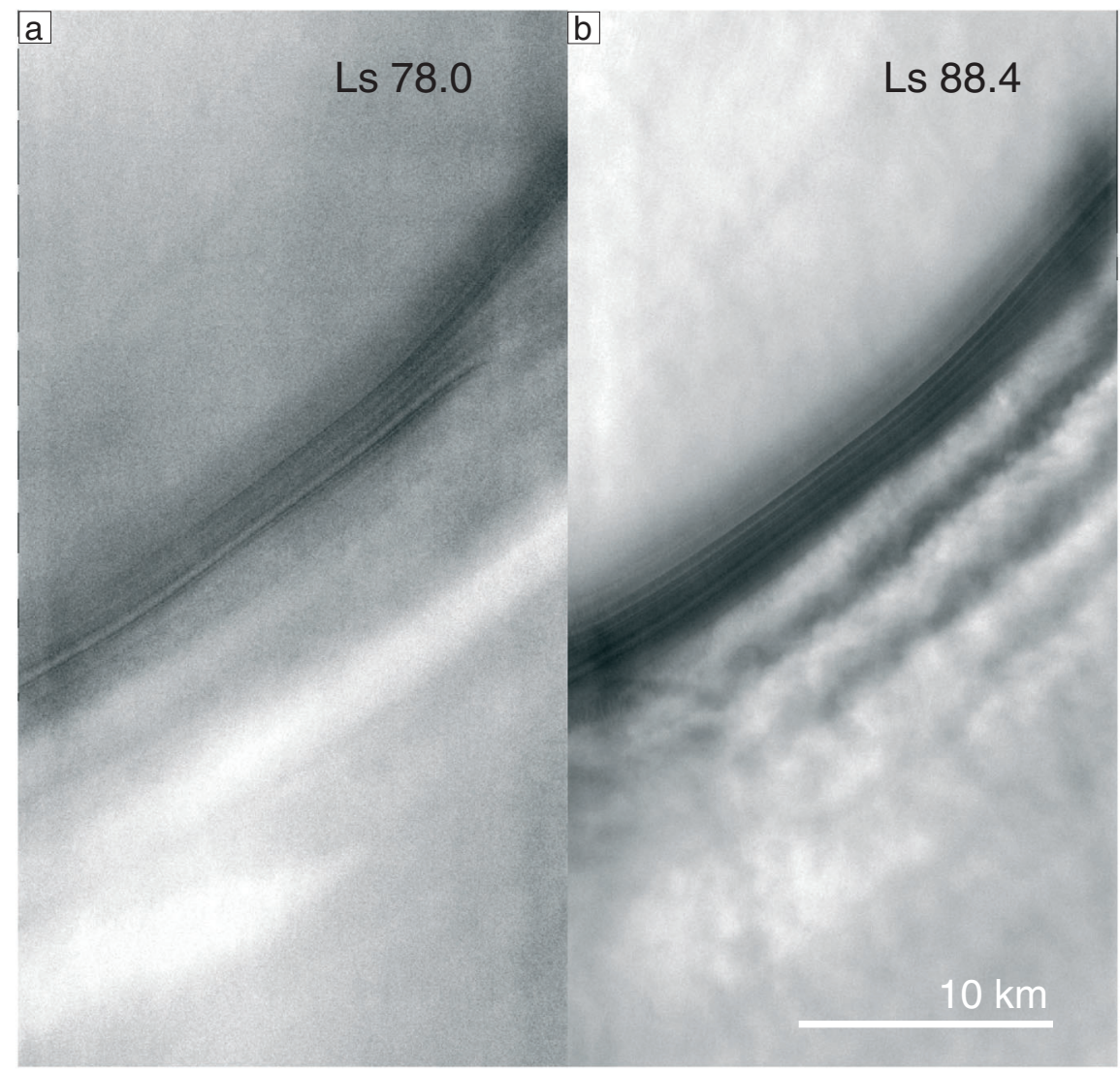

Figure 5. THEMIS observations of a trough with and without cloud cover. (a) Portion of THEMIS image V28633004 taken during Mars year 29 at $\mathrm{L}_{\mathrm{s}}$ 78.0. Seasonal frost covers the low side and a portion of the high side of the trough. (b) Portion of THEMIS image V28920037 taken during Mars year 29 at $\mathrm{L}_{\mathrm{s}} 88.4$, less than $5 \mathrm{~h}$ prior to Figure 6a. Undular clouds cover the low side of the troughs. Footprint for Figures $5 \mathrm{a}$ and $5 \mathrm{~b}$ is the same. Locations in Figures $1 \mathrm{a}$ and $6 \mathrm{~b}$.

\subsection{Seasonality of NPLD Cloud Cover}

[20] The total number of observations is much greater for THEMIS than all other imaging instruments combined. Due to that and our need for high sampling frequency, our analyses are primarily based on these images. Occasionally, THEMIS images of the NPLD are acquired every $2 \mathrm{~h}$ for up to $12 \mathrm{~h}$ (Figure 8). Analysis of images across multiple years provides insight into the seasonal timing of cloud abundance (Figure 9). All images capturing clouds were acquired between $L_{s} 24$ and $L_{s} 102$, with the first appearance of trough-parallel clouds at $\mathrm{L}_{\mathrm{s}} 36$.

[21] Of the Mars years with available north polar THEMIS imagery, MY 26, 27, 28, 29, 30, and 31, there are 0, 52, 25, 133, 54, and 96 detections of trough clouds, respectively (Table 1). During MY 26, only 21 images were taken during the cloud season, hampering detection. For the date range between $\mathrm{L}_{\mathrm{s}} 24$ and $\mathrm{L}_{\mathrm{s}} 102$, MY 27 has 927, MY 28 has 559, MY 29 has 1622, MY 30 has 673, and MY 31 has 708 available images (Table 1). Combining all years for analysis, $\mathrm{L}_{\mathrm{s}}$ range 80-90 has the highest frequency with over 180 observed clouds (Figure 9). $\mathrm{L}_{\mathrm{s}}$ range $90-100$ has $\sim 70$ detections, and Ls range $70-80$ has $\sim 50$. There are no trough- parallel clouds detected after $\mathrm{L}_{\mathrm{s}} 102$.

[22] Most clouds are only captured in a single image, but for the solar longitude range $\mathrm{L}_{\mathrm{s}} 84.66$ to 87.98 in Mars year 29, every visible wavelength image north of $86^{\circ}$ contains trough-parallel clouds. Many others before and after also contain clouds. This extreme duration (a span greater than $200 \mathrm{~h}$ ) is only observed once in the 6 Mars years that have been examined. Images taken during this period from HRSC (Figure 6), THEMIS infrared bands, and the Compact Reconnaissance Imaging Spectrometers for MARS also capture this event.

[23] The geographic pattern of trough cloud detections is shown in Figure 10. During the 5 Mars years with sufficient imagery, most of the NPLD troughs experienced trough clouds. However, fewer detections were found in Gemina Lingula and in smaller regions at the margins near $90^{\circ} \mathrm{E}$ and $255^{\circ} \mathrm{E}$. Relative infrequency of events at these locations or sampling bias may have contributed to this distribution of nondetection.

\subsection{Observations in the South}

[24] More than 14,000 THEMIS images cover portions the SPLD, and a preliminary search for trough clouds has been undertaken. In a strategic survey, $\sim 250$ images containing trough-parallel clouds are found in Mars years 26-29 (Figure 11). Fewer than 20 images capture transverse or wispy clouds.

[25] Preliminary results indicate that, like on the NPLD, all of the trough-parallel clouds in the south are near topographic changes such as troughs, craters, and scallops (Figure 11). 


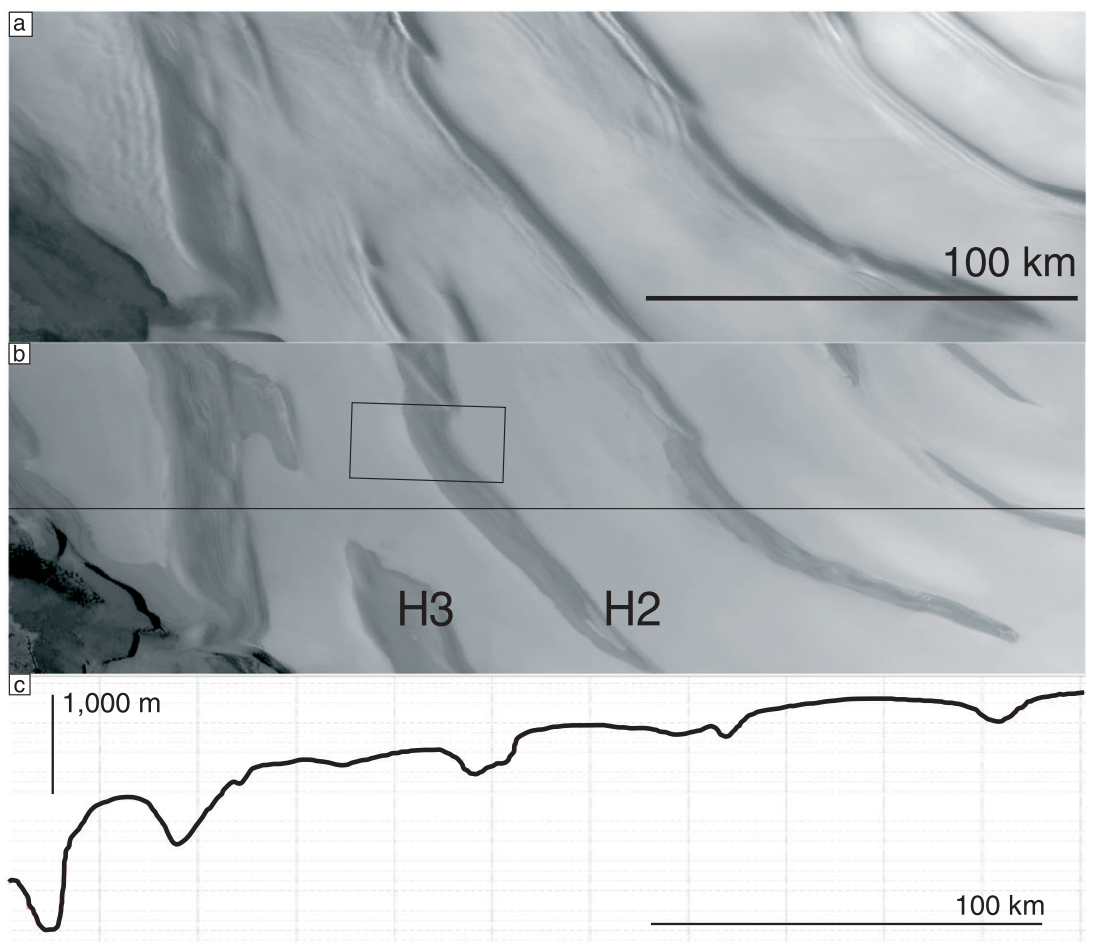

Figure 6. Troughs clouds north of Chasma Boreale. (a) Portion of H5741_0000_ND2 taken during Mars year 29 at $\mathrm{L}_{\mathrm{s}} 88.4$, just $5 \mathrm{~h}$ after Figure $5 \mathrm{~b}$. Undular trough clouds are visible at the bottom of at least six troughs over $300 \mathrm{~km}$. (b) Portion of H1167_000_ND2 taken during Mars year 27 at L 129 .4. Same location as in Figure 6a but at a later time in the year. Clouds do not cover the surface. The contrast between Figures $6 \mathrm{a}$ and $6 \mathrm{~b}$ demonstrates temporary nature of trough clouds. Horizontal line is the approximate cross section corresponding to Figure $6 \mathrm{c}$. Rectangle is footprint of Figure $5 \mathrm{c}$. Topographic profile of horizontal line in Figure 6b. More than $1000 \mathrm{~m}$ of elevation separate the northernmost trough from the southernmost trough. Because the clouds of Figure $6 \mathrm{a}$ are strongly affected by topography, it is unlikely that they reside at the boundary layer or $4 \mathrm{~km}$ elevation [Whiteway et al., 2009]. Locations of Figures 6a and 6b indicated in Figure 1a.

They appear at $\mathrm{L}_{\mathrm{s}}$ ranges, $\mathrm{L}_{\mathrm{s}} 212-278$, and 282-317. The early range corresponds to southern spring, which is similar to our findings in the northern cloud study. However, the later range of $\mathrm{L}_{\mathrm{s}}$ does not have a northern equivalent. Clouds observed between $\mathrm{L}_{\mathrm{s}} 282$ and 317 are uniformly at higher elevations and nearer to the residual $\mathrm{CO}_{2}$ ice cap than earlier clouds (Figure 11c). Trough clouds at the highest elevations on the SPLD may be $\mathrm{CO}_{2}$ ice rather than $\mathrm{H}_{2} \mathrm{O}$ ice or relate to summertime $\mathrm{CO}_{2}$ sublimation.

\section{Interpretations and Katabatic Jumps}

\subsection{Ice Cloud Formation}

[26] The clouds observed in Figures 4c, 5b, 6a, 7, and 8 are most likely composed of water-ice crystals and some fraction of dust. A water-ice composition is assumed because in late spring, the temperatures in the north polar region are far too high for solid $\mathrm{CO}_{2}$ ice. The existence and properties of water-ice clouds depend on several factors: ambient vapor concentration, pressure, temperature, and the number of cloud condensation nuclei [Toon et al., 1989; Montmessin et al., 2004]. While a discussion of ice cloud microphysics is beyond the scope of this paper, it is important to note some implications of clouds existence. In particular, conditions are met for enhanced sublimation of water from the surface and ice crystals grow to sufficient size for an optically thick cloud to form. This implies that specific meteorological conditions are occasionally favorable to yield the formation of lowaltitude trough clouds.

[27] We interpret the trough- parallel clouds as being primarily ice, but a previous interpretation suggested that they could be dust clouds [Warner and Farmer, 2008]. We have no spectral analysis to contradict that claim, but the morphology of the clouds goes against this argument. Trough clouds are typically elongated along trough and have very little extent in the cross-trough direction (Figures $8 \mathrm{~b}$ and $8 \mathrm{~m})$. This is consistent with cloud formation caused by wind and temperature disturbances associated with katabatic jumps (see section 4.3) rather than the purely Aeolian erosion that yields dust clouds. We have detected other cloud morphologies on both poles that are more consistent with dust clouds (Figure 12). These clouds are elongated cross trough for many tens of kilometers and are more frequent on the SPLD than the NPLD. As expected, the existence of dust clouds indicates the ability of wind to scour dust from a trough. The long extent of the clouds suggests that dust is not immediately redeposited and may be removed entirely from the cap, in agreement with spectral analysis of deposits [Massé et al., 2012]. Katabatic jumps are not present for these events. 


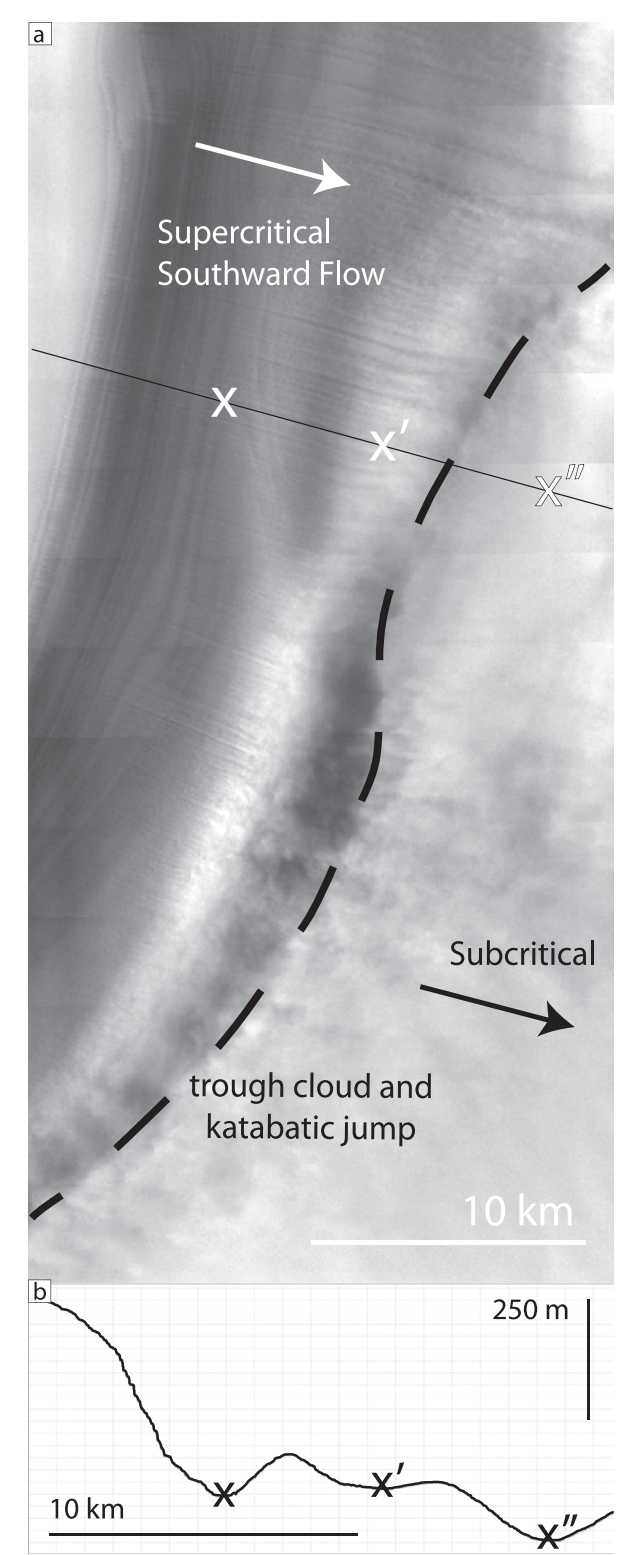

Figure 7. Trough cloud with linear streaks. (a) Portion of THEMIS VIS image V12295001 taken during Mars year 27 at $\mathrm{L}_{\mathrm{s}}$ 90.6. Winds enter the trough from the high side (left). The flow accelerates downhill toward the trough bottom (white Xs indicate local minimum elevations). The cloud shape is indicative of a katabatic jump separating subcritical and supercritical flow. Shadows and turbulence suggest that this is not part of the surface. Toward the high side from the katabatic jump, linear rolls are separated by 300 to $500 \mathrm{~m}$. These rolls have shadows, indicating they reside at low elevations above the layered terrain. If the clouds were higher, the shadows would be displaced greatly from the individual roll. Fewer than 5 of the $\sim 350$ images of NPLD clouds exhibit linear rolls on the high side, exemplifying the rarity of this observation. (b) Topographic profile of vertical line in Figure 7a. Black Xs mark the relatively lowest elevations in the trough and correspond to the White Xs in Figure 7a. Location given in Figure $1 \mathrm{a}$.
[28] Terrestrial clouds similar in morphology to the Martian trough clouds are found in Antarctica and often form elongated "walls of snow," especially close to large slope changes [Lied, 1964] (Figure 13). Those distinctive clouds result from a local enhancement of katabatic winds and formation of "katabatic jumps," also called Loewe effect [Pettré and André, 1991]. Strong perturbations of temperature, pressure, and wind velocity associated with this phenomenon could explain the formation of walls of snow. We propose that Martian trough clouds follow an analogous mechanism.

\subsection{Katabatic Winds}

[29] Some of the most common winds on long regional planetary slopes are katabatic. These result from downhill flow of cold, dense air (radiatively cooled over the ice cap) beneath ambient, warmer air. Large elevation differences and temperature changes required to form these winds mean that they are most often found on Earth near elevated ice sheets. Ice sheets offer favorable conditions due to high thermal inertia and high albedo, both contributors for strong katabatic winds. Much effort has gone into studying such winds in Antarctica [Ball, 1956; Lied, 1964; Pettré and André, 1991].

[30] The duration of katabatic winds on Earth has been recorded from several to tens of hours. Winds vary predictably in strength on both diurnal and seasonal time scales [Pettré et al., 1993]. Terrestrial katabatic winds are strongest near the equinoxes, likely due to larger scale atmospheric phenomena occurring at that time. Diurnal variations are most directly linked to insolation. Wind direction is influenced both by the downhill katabatic acceleration and deflection by the Coriolis force [Pettré et al., 1993].

[31] Short radiative time scales and low thermal inertia of the Martian $\mathrm{CO}_{2}$ atmosphere result in katabatic winds that are more frequent and intense on Mars than on Earth (Gierasch and Sagan [1971]; see Spiga [2011] for a comparative discussion). This occurs in both polar regions and at lower latitudes. Katabatic wind strength and directions have been modeled on the NPLD during the springtime [Tyler and Barnes, 2005; Spiga et al., 2011]. Similarities exist between the modeled winds of Mars and those observed in Antarctica. For example, maximum velocities are found in both cases at the bottom of steep slopes and the Coriolis force along with local and regional topography affects the wind directions (Figure 14). In the model presented by Spiga et al. [2011], the maximum velocities attained by polar katabatic winds at the bottom of troughs were $10-12 \mathrm{~m} / \mathrm{s}$. Velocities on the low side of troughs were near $4-6 \mathrm{~m} / \mathrm{s}$. Such a katabatic wind regime develops from the surface to about $1 \mathrm{~km}$ above the surface. Those estimates represent the regional component of katabatic winds, obtained by a model with spatial resolution $10-20 \mathrm{~km}$.

[32] To better simulate the conditions on the NPLD, we used the same model with a spatial resolution of $2.2 \mathrm{~km}$. Higher resolution better represents the effects of topography and slopes and shows an enhancement of wind speed contrast across troughs in our simulations. Wind velocities in excess of $18 \mathrm{~m} / \mathrm{s}$ are modeled on trough high sides, while velocities reach as low as $1 \mathrm{~m} / \mathrm{s}$ on the low sides (Figure 14d). Strong winds over the polar caps might also occur at other seasons due to large-scale atmospheric conditions [Tyler and Barnes, 2005], but clouds are not observed at those times, 


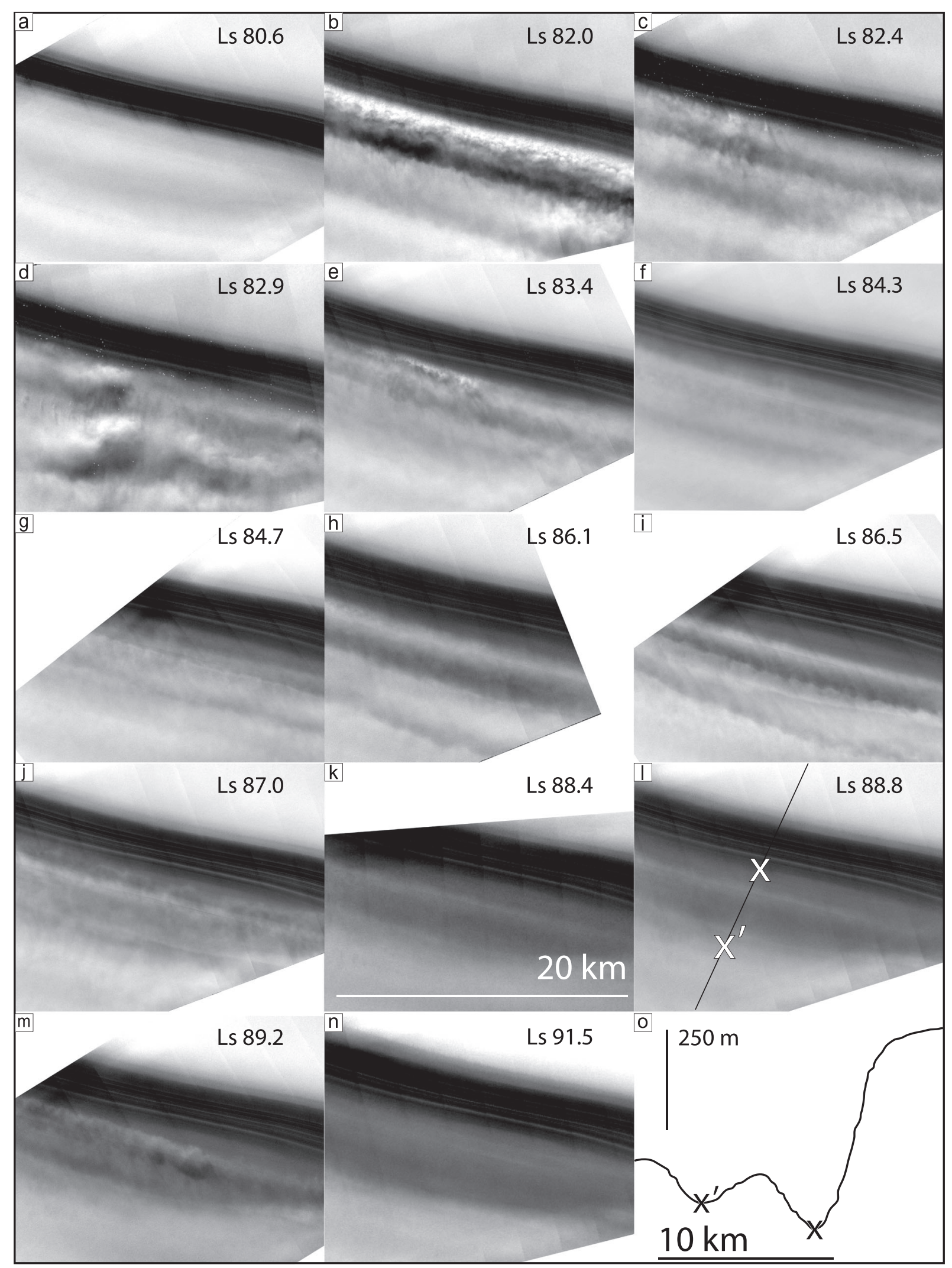

Figure 8 


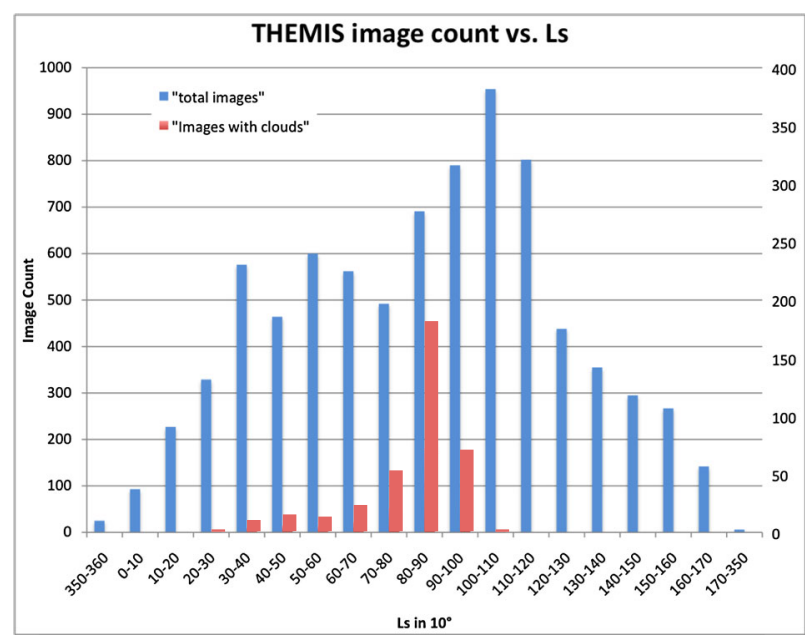

Figure 9. Temporal histogram of clouds. The 8105 THEMIS VIS images exist and were examined for latitudes north of $82^{\circ}$ during Mars years 26-31 (blue). More than 350 images capture clouds similar to those depicted in Figure 4 (red). Clouds imaged by THEMIS begin after $\mathrm{L}_{\mathrm{s}}$ 24 , peak between $L_{s} 80$ and 90 , and end abruptly near $L_{s}$ 100. The last trough cloud is observed at Ls 102 .

and it is unlikely that they contribute to the observed regularity of the trough features.

[33] Katabatic winds act to increase sublimation from the surface in several ways. First, the downslope winds warm the local atmosphere due to adiabatic heating. Second, sensible heat is transferred into the NPLD surface [Spiga et al., 2011]. Spiga et al. [2011] found that in normal conditions at $\mathrm{L}_{\mathrm{s}} 60$, as much as $15 \mathrm{~W} \mathrm{~m}^{-2}$ of energy was added to the surface - or approximately $6 \%$ of the total energy from insolation at summer solstice near the North Pole $\left(250 \mathrm{~W} \mathrm{~m}^{-2}\right.$ at $\mathrm{L}_{\mathrm{s}}$ 90) [Laskar et al., 2002]. These are low estimates, given that local slope enhancements are too small to be resolved in the mesoscale model, and seasonal contrasts are not part of this study. Finally, moving, dry air has a direct effect on transfer coefficients of water vapor between the surface and the atmosphere, enhancing sublimation again.

\subsection{Katabatic Jumps}

[34] Lied [1964] and Pettré and André [1991] studied clouds in Antarctica that are similar in orientation and topographic setting to the trough clouds we find on the NPLD. The clouds were perpendicular to the katabatic flow and formed near changes in topography. The observed clouds appeared at a point the authors describe as a katabatic jump (Figure 13) and fall within the class of internal hydraulic jumps described by Turner [1979]. Pettré and André [1991] define a katabatic jump as "a narrow zone with large horizontal changes in wind speed, pressure, and temperature." While atmospheric flow speed and temperature decrease across a katabatic jump, pressure and flow thickness increase [Lied 1964]. Pettré and André [1991] observed velocities that decreased from $\sim 20$ to $\sim 5 \mathrm{~ms}^{-1}$ over a short distance and flow thicknesses that tripled from 400 to $1250 \mathrm{~m}$.

[35] We interpret the trough-parallel clouds in Figures 4c, $5 \mathrm{~b}, 6 \mathrm{a}, 7 \mathrm{a}, 8$, and 11 to be caused by katabatic jumps. The simplest model to derive first-order physical characteristics of katabatic jumps is based on an analogy with hydraulic jumps, e.g., in rivers [Ball, 1956] (Figure 15). This is the model on which we base present discussions, but future work will involve high-resolution mesoscale simulations to refine our analysis.

[36] In fluid dynamics, hydraulic jumps are defined as "discontinuous transitions from [Froude] supercritical to [Froude] subcritical flow in an open channel" [Hager, 1992]. Froude numbers $(F r)$ are mostly simply defined as the dimensionless ratio of fluid speed $(U)$ to celerity $(c)$, where celerity is the speed of propagation of a gravity wave in a fluid:

$$
F r=\frac{U}{c}
$$

[37] Supercritical flow has velocity greater than the celerity in a given fluid and is thus characterized by a Froude number $>1$. Subcritical flow moves slower than the celerity and has Froude number $<1$. Flows with Froude numbers $>=1$ do not transmit information upstream. In the case of two-phase flow, or a solid suspended in a fluid, the densimetric Froude number, $F r_{d}$, is used. It is defined as

$$
F r_{d}=\frac{U}{\sqrt{h \cdot g^{\prime}}}
$$

Table 1. Number of Trough Cloud Observations for Mars Years $26-31^{\mathrm{a}}$

\begin{tabular}{lcccc}
\hline Mars Year & Total Images & $\mathrm{L}_{\mathrm{s}}$ 24-102 & Trough Clouds & $\begin{array}{c}\text { Percentage } \\
\text { in } \mathrm{L}_{\mathrm{s}} \text { 34-98 }\end{array}$ \\
\hline 26 & 177 & 21 & 0 & 0 \\
27 & 2985 & 927 & 52 & 5.6 \\
28 & 909 & 559 & 25 & 4.5 \\
29 & 2101 & 1622 & 133 & 8.2 \\
30 & 948 & 673 & 54 & 8.0 \\
31 & 985 & 708 & 96 & 13.6 \\
& 8105 & 4510 & 360 & \\
\hline
\end{tabular}

${ }^{a}$ Total number of THEMIS VIS images at latitudes $>82^{\circ} \mathrm{N}$; available images between $\mathrm{L}_{\mathrm{s}} 24$ and 102, images observing trough clouds, and percentage of images containing clouds during cloudy season (Figure 9).

Figure 8. Sequence of THEMIS images for trough during the cloud season. (a) to (n) THEMIS images with same footprint: V28706003, V28744006, V28756004, V28769004, V28781003, V28806003, V28818007, V28856007, V28868003, V28881003, V28919037, V28931004, V28943004, V29006006 during Mars year 29 from $\mathrm{L}_{\mathrm{s}} 80.6$ to $\mathrm{L}_{\mathrm{s}} 91.5$. Trough clouds exhibit strong morphological changes during this period. Images are individually stretched, making albedo changes difficult to detect; however, from Figures 8 a to 8n, the low side of this trough gradually decreases albedo, while the high side changes little. The albedo change is the result of mantling from fresh deposition of ice and dust. (o) Topographic profile of vertical line in Figure 81. Xs mark the local minimum elevations in the trough and correspond to the White Xs in Figure 81. See Figure 1a for location. 


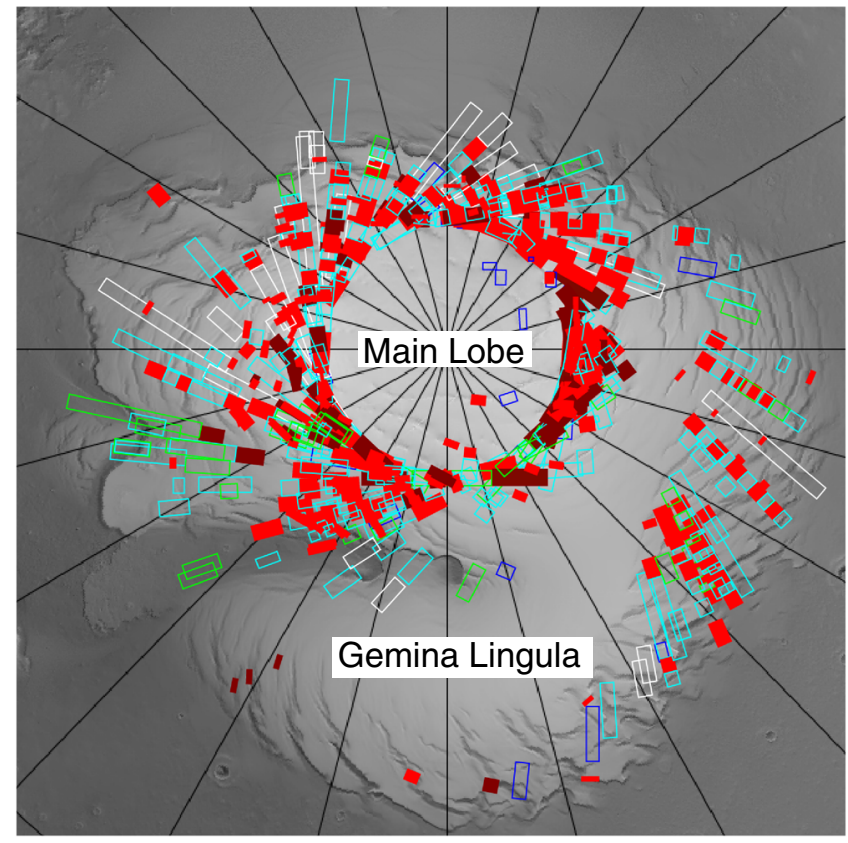

Figure 10. Location map of images with detected clouds on the NPLD. Red boxes indicate locations of trough-parallel cloud. Dark red indicates undular clouds. Blue and green indicate general cloudiness and streaks, respectively. Gemina Lingula and the region extending to the main lobe have sparse detections. No images are available from THEMIS for latitudes north of $\sim 87^{\circ}$ before Mars year 31 .

where $h$ and $g^{\prime}$ are the flow thickness and reduced gravitational acceleration, respectively. In turn,

$$
g^{\prime}=\frac{g\left[\left(\rho_{1}-\rho_{2}\right) \cdot C-\left(\rho_{2}-\rho_{3}\right) \cdot(1-C)\right]}{\rho_{3}}
$$

where $\rho_{1}$ is the density of the sediment suspended in the flow, $\rho_{2}$ the density of katabatic flow, $\rho_{3}$ the ambient air in the absence of flow, and $C$ is the volumetric concentration of sediment, expressed as $\mathrm{m}^{3} / \mathrm{m}^{3}$.

[38] As for hydraulic jumps, the Froude number upstream of the katabatic jump is greater than 1 and the Froude number downstream is less than 1. Cloud morphologies in Figures 4c, $5 \mathrm{~b}, 6 \mathrm{a}$, and 12 allow for a more precise estimate of the highside Froude number. In those observations, the cloud has an undular or wavelike appearance. Several investigations have studied similar undulations in hydraulic jumps and found them associated with Froude numbers between 1.25 and 1.7 [Andersen, 1978; Ohtsu et al., 2001]. With Froude numbers $<1.25$, the flow surface is smooth and unbroken, corresponding to a poorly defined undular jump. Froude numbers $>1.7$ will exhibit sharp, well-defined jumps and become highly turbulent [Ball, 1957].

[39] The majority of observed parallel troughs clouds, approximately $80 \%$, do not have undular characteristics. This sets the lower bound of high-side Froude number for those clouds at 1.7 and leaves open the possibility of Froude numbers much higher. Froude numbers for winds above strong katabatic jumps on Earth have been measured, with values that range from 3.4 [Pettré and André, 1991] to 18 [Ball, 1957]. Froude numbers from our simulations reach $\sim 5$
[Pettré and André, 1991, equation (0)] (Figure 14e); therefore, we adopt $F r_{d}=5$ as an upper bound for katabatic flow on the NPLD, giving a range of 1.7 to 5. Froude numbers between $\sim 1$ and 1.7 are also possible, but we observe conditions indicating such values relatively infrequently and treat them as special cases.

\subsection{Flow Depths}

[40] We interpret the transverse linear streaks visible in Figure 7 [Smith and Holt, 2010, Figure 4] to be rolls (i.e., horizontal vortices) that align with the wind direction. Rolls occurring in natural systems have a ratio of separation to flow depth of 1:2 [Fedele and García, 2009], allowing for a rough estimate of wind depth. Applying this rule to rolls separated by $300-500 \mathrm{~m}$, we estimate a flow depth of 150 to $250 \mathrm{~m}$ and adopt $200 \mathrm{~m}$ for reference. Rolls are rarely observed, but there is no other method for obtaining flow depth by direct observation, so we rely on this estimate (and concurring results from atmospheric modeling) in calculations presented below.

[41] Linear rolls may be used to estimate the flow depth of the incoming wind, but no measurements, either direct or indirect, are yet possible for the height of a katabatic jump on Mars. Instead, in this frame of our simplified hydraulic jump model, we rely on the Bélanger conjugate depth equation [Pettré and André, 1991, equations (4) and (9)], which specifies the ratio of thickness of flow post hydraulic jump to that of the incoming flow [Hand, 1974; Hager, 1992]. That is,

$$
\frac{h_{2}}{h_{1}}=\frac{\sqrt{1+8 F r_{1}^{2}-1}}{2}
$$

where $h_{2}$ is the flow depth post hydraulic jump and $h_{1}$ and $F r_{1}$ are the prejump flow depth and Froude number, respectively.

[42] Applying the 1.7 to 5 range of Froude numbers and incoming flow depths of $200 \mathrm{~m}$, the post hydraulic jump depth is estimated to range from $400 \mathrm{~m}$ to $1300 \mathrm{~m}$. This represents a flow depth ratio from post to prejump of $\sim 2-6.5$. Our simulations of the katabatic wind depths are consistent with these estimates.

\subsection{Duration and Frequency of Clouds}

[43] Figure 6a displays trough clouds over at least six troughs, spanning an area of $\sim 300$ by $200 \mathrm{~km}$, the largest area imaged with multiple trough clouds (all THEMIS observations cover a smaller area). The discovery of contemporaneous trough clouds in extended images suggests that a combination of specific large-scale, mesoscale, and local meteorological phenomena allows for their formation. Similar to findings from terrestrial studies [Pettré et al., 1993], we conclude that the duration of trough clouds can be several hours (and perhaps in exceptional conditions, several days) because slow, large-scale atmospheric processes play an important role. Meteorological modeling indeed shows that regional katabatic winds can be enhanced by large-scale weather systems such as baroclinic waves, planetary waves, and transients [Tyler and Barnes, 2005], which may explain the seasonality of katabatic jumps and trough cloud observations.

[44] Direct comparison between multiple images of the same location is difficult due to lighting and other conditions, but detection of clouds is less ambiguous than other 


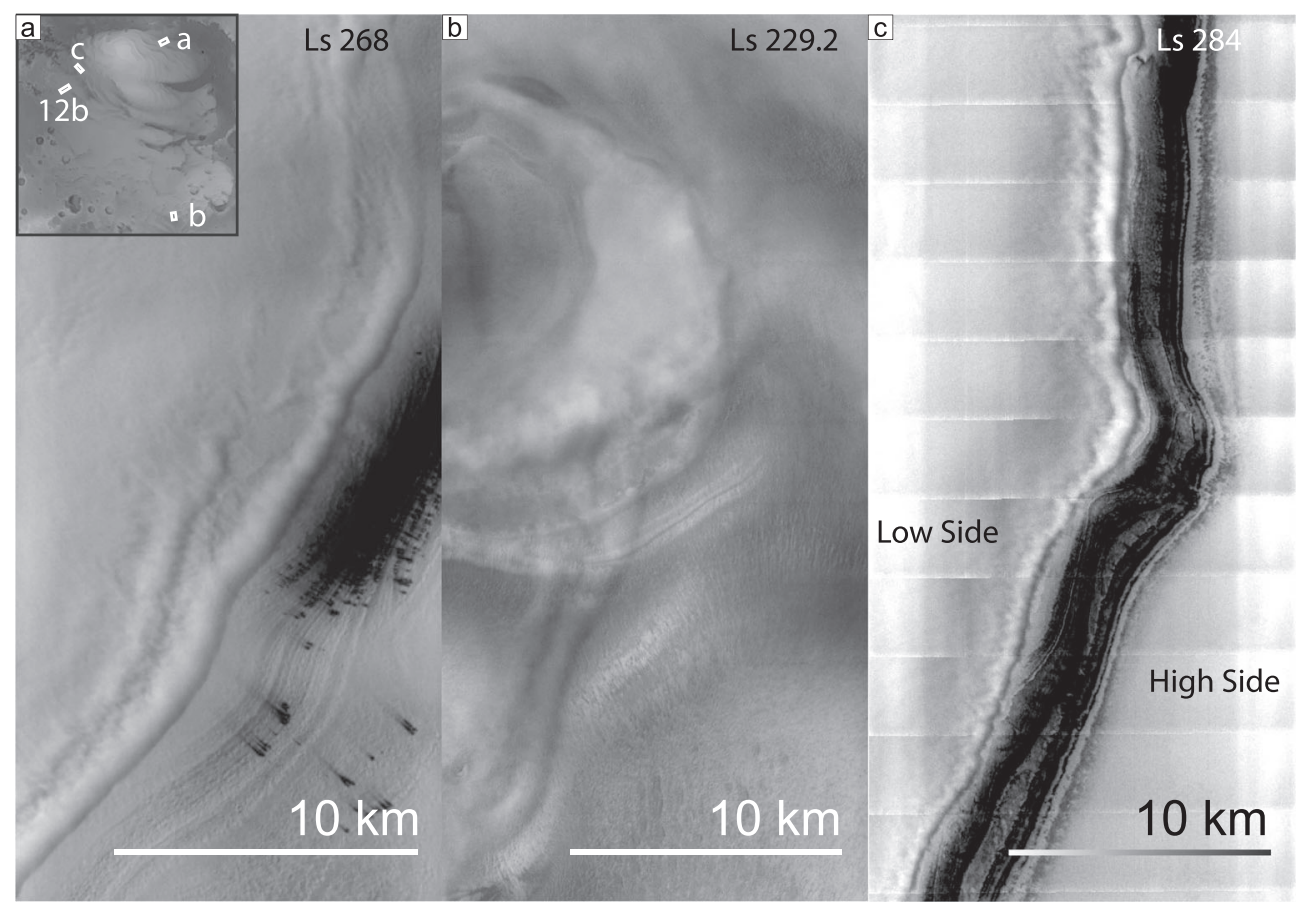

Figure 11. South polar trough clouds. (a) THEMIS VIS image V16249003 taken during Mars year 27 at $\mathrm{L}_{\mathrm{s}}$ 268. Trough clouds are found on the SPLD in southern spring and are manifested similar to those in the north. Wind streaks indicate wind direction from lower right toward upper left. (b) Portion of THEMIS VIS image V07160010 taken during Mars year 26 at $\mathrm{L}_{\mathrm{s}}$ 229.2. Clouds form at katabatic jump near scalloped terrain of SPLD and have undular form, similar to NPLD observations. (c) Portion of THEMIS VIS image V08216005 taken during Mars year 26 at $\mathrm{L}_{\mathrm{s}} 284$. Trough cloud, on low side, follows topography. Cloud changes from simple to undular jump (moving upward from bottom of the image), indicating slight changes in flow conditions and hence, Froude number. Locations indicated in inset of Figure 11a.

observations such as albedo or topography. In fact, the temporary nature of clouds makes their absence much easier to detect (Figures 5, 6, and 8). By examining sequential images over neighboring sites, we determine that typical clouds are often visible for 10 to $20 \mathrm{~h}$. One event in Mars year 29 is observed in every image north of $86^{\circ}$ for nearly 20 Martian Sols (Figure 8 ). While duration and intensity vary considerably, we adopt $10 \mathrm{~h}$ to conservatively represent the duration of a standard event for future sections.

[45] The frequency of storms may only be determined by examining a time series of images taken at the same location. This is difficult because observations of the same location are not often repeated on a short time scale; however, overlapping or adjacent images can be sufficient for making an estimate. In general, locations closer to the pole experience more events, while those between troughs, at lower elevations, or in lowslope regions will experience fewer. We find that at any given trough, several events may be observed in 1 Mars year, but zero maybe be observed in another year. We therefore estimate, in an attempt to be conservative, that most troughs experience one trough cloud per year.

[46] Making observations from orbit, especially of events that are short lived, can be expected to result in incomplete surveys. Until observations from the ground are possible, estimates of frequency will be based on few data points and sparse coverage. Additionally, adequate sampling in this survey only spans 5 Mars years, leaving open the possibility that these were anomalous. Given the limitations and understanding that variations based on latitude are likely, we feel confident in estimating approximately one event of $\sim 10$ $h$ occurs at a typical site on the NPLD per year.

\section{Discussion and Cyclic Step Framework}

\subsection{Cyclic Steps}

[47] Cyclic steps are described as "a train of upstreammigrating bed undulations bounded by hydraulic jumps" (Figures 15c and 16) [Parker, 1996; Kostic et al., 2010]. Although not so named, they were first recognized as a distinct bed form by Winterwerp et al. [1992]. Fundamentally, cyclic steps are bed forms that exist due to the erosion, transport, and redeposition of sediment. Unlike dunes, where material is removed from the stoss slope and redeposited on the lee, Aeolian cyclic steps behave in the opposite manner. Nevertheless, the same properties exist in each: erosion occurs as accelerating winds pick up material, and deposition occurs at sites of decelerating winds. For example, katabatic jumps represent the point of sudden deceleration for winds at the bottom of troughs (Figure 16).

[48] Cyclic steps are considered permanent, long-wave features, distinguishing them from their short-lived counterpart, antidunes. Antidunes are a train of smoothly rounded bed forms [Hand et al., 1972; Hand, 1974] that tend to be unstable and short lived [Kostic et al., 2010]. In cyclic steps, hydraulic jumps separate the fast-moving, Froude supercritical flow (red in Figure 16) from relatively slow moving Froude subcritical 


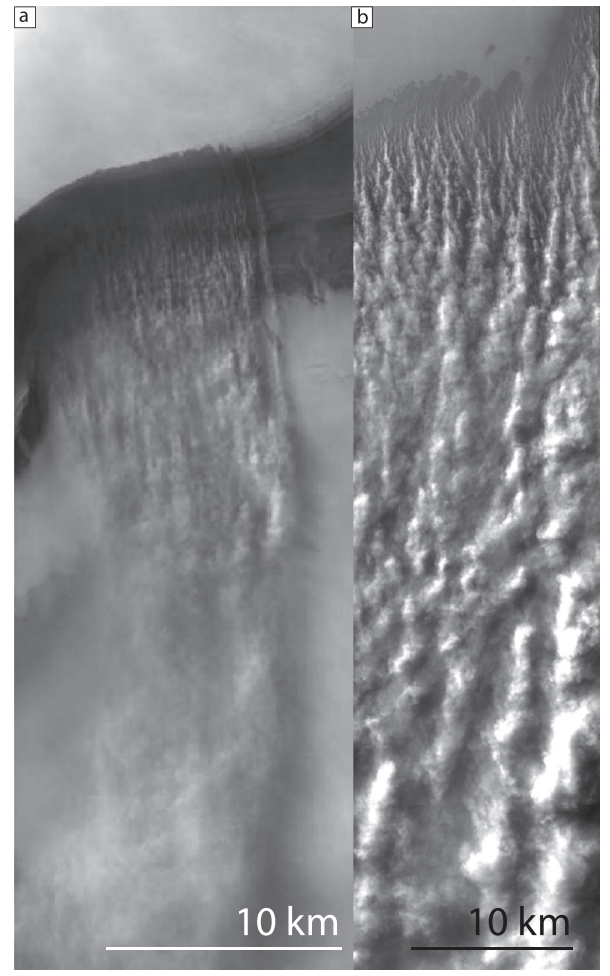

Figure 12. Elongated clouds emanating from trough high sides. (a) Portion of HRSC image H3670_000 taken during Mars year 28 at $\mathrm{L}_{\mathrm{s}} 135.9$ on the NPLD. (b) Portion of THEMIS image V08874006 over SPLD taken during Mars year 26 at Ls 316.3. The clouds in Figures 12a and 12b are very distinct from the parallel trough clouds discussed in this paper, aligning perpendicular to troughs and extending tens of kilometers beyond. Because they are so distinct, we do not consider them to be a part of the cyclic step story. They may be examples of dust plumes as described by Warner and Farmer [2008]. Locations of Figure 12a in Figure 1a and Figure 12b in Figure 11a inset.

flow (blue in Figure 16) [Kostic et al., 2010]. At the hydraulic jump, the flow rapidly decelerates upon encountering the adverse slope. Between the troughs, subcritical flow (green) continues until the process repeats by accelerating into another step (red).

[49] 2-D cyclic step models have been validated for terrestrial systems in flume experiments [Taki and Parker, 2005; Spinewine et al., 2009] and in numerical models [Sun and Parker, 2005; Kostic and Parker, 2006]. These steps can form under net erosional conditions [Parker and Izumi, 2000], net depositional conditions [Kostic and Parker, 2006], and conditions that are in equilibrium when averaged over the steps [Taki and Parker, 2005].

[50] Terrestrial features attributed to hydraulic jumps and having similar stratigraphic and accumulation patterns to the spiral troughs are found in Antarctic ice [Swithinbank et al., 1988; Fahnestock et al., 2000; Frezzotti et al., 2002], subaerial streams (Figure 15c)[Kostic et al., 2010], and submarine sediments [Normark et al., 1980; Nakajima et al., 1998; Lee et al., 2002]. Features in submarine systems are called sediment waves and have been studied in detail [Lee et al., 2002; Migeon et al., 2000] (Figure 17a). They are classified as a subcategory of cyclic steps that exist in a depositional regime [Kostic et al., 2010]. Sediment waves have smaller amplitudes (by a factor of $\sim 100$ ) and wavelengths (by a factor of $\sim 10$ ) than the spiral troughs, but the topographic and stratigraphic similarities are striking (Figure 17a) [Frezzotti et al., 2002; Smith and Holt, 2010]. In ice, features called megadunes also resemble the spiral troughs, and their origin has been linked to katabatic winds, but detailed studies of their formation have not yet been undertaken [Fahnestock et al., 2000; Frezzotti et al., 2002].

[51] Models applied to net depositional systems for sediment waves reproduce stacked morphologies and topographic patterns [Fildani et al., 2006] that are qualitatively similar to those observed in SHARAD data beneath the spiral troughs on the NPLD (Figures 2, and 17). Sediment waves form when higher-density, sediment-laden water flows beneath the ambient fluid of normal density [Kuenen, 1951; Mohrig and Marr, 2003]. These flows, called turbidity currents, carry excess weight of sediment and accelerate downhill due to higher density, depositing the sediment at hydraulic jumps [Parker et al., 1986; Kostic et al., 2010]. In the Martian case, dense air, rather than water, flows directly over the surface as a katabatic wind, analogous to turbidity currents [Zammett and Fowler, 2007].

[52] Erosional cyclic steps behave differently from their depositional counterpart. On Earth, they are most often observed as chute-pool morphologies or considered to be "discontinuous gullies" [Reid, 1989]. Even though they are exposed to supercritical flow, they evolve into a series of steps that migrate slowly upstream and are bounded by hydraulic jumps; no sediment is deposited to leave a stratigraphic record. Stratigraphy associated with erosional steps will not exhibit asymmetric accumulation or offset layering as seen in depositional systems. Only a morphology of evenly spaced, periodic headcuts (in two dimensions) will be exhibited [Parker and Izumi, 2000].

[53] Unlike in the depositional case where sediment is deposited at the hydraulic jump, suspended sediment remains

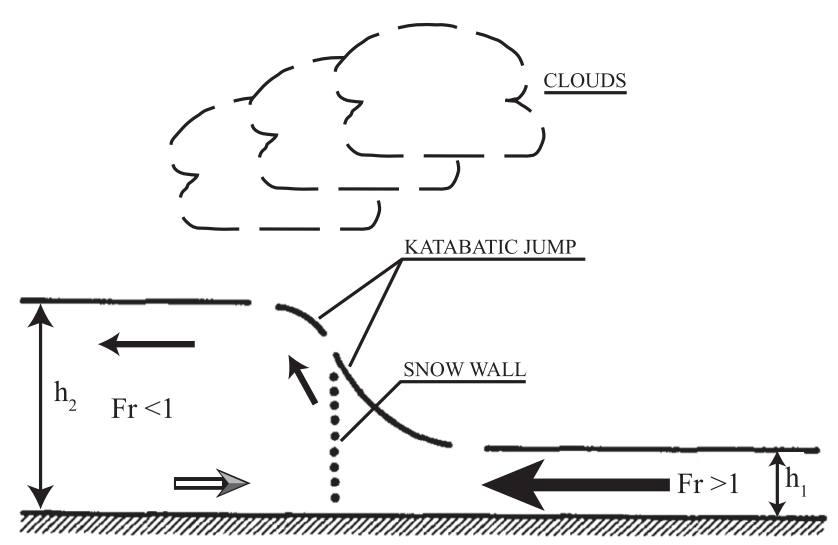

Figure 13. Cartoon depiction of Aeolian katabatic jump in Antarctica. Right to left, incoming flow is supercritical. Flow depth increases at the katabatic jump. Ice forms at snowline, and clouds form at site of katabatic jump. Downstream of the katabatic jump flow is subcritical. Arrows indicate flow direction. Reproduced with permission from Pettré and André [1991]. 


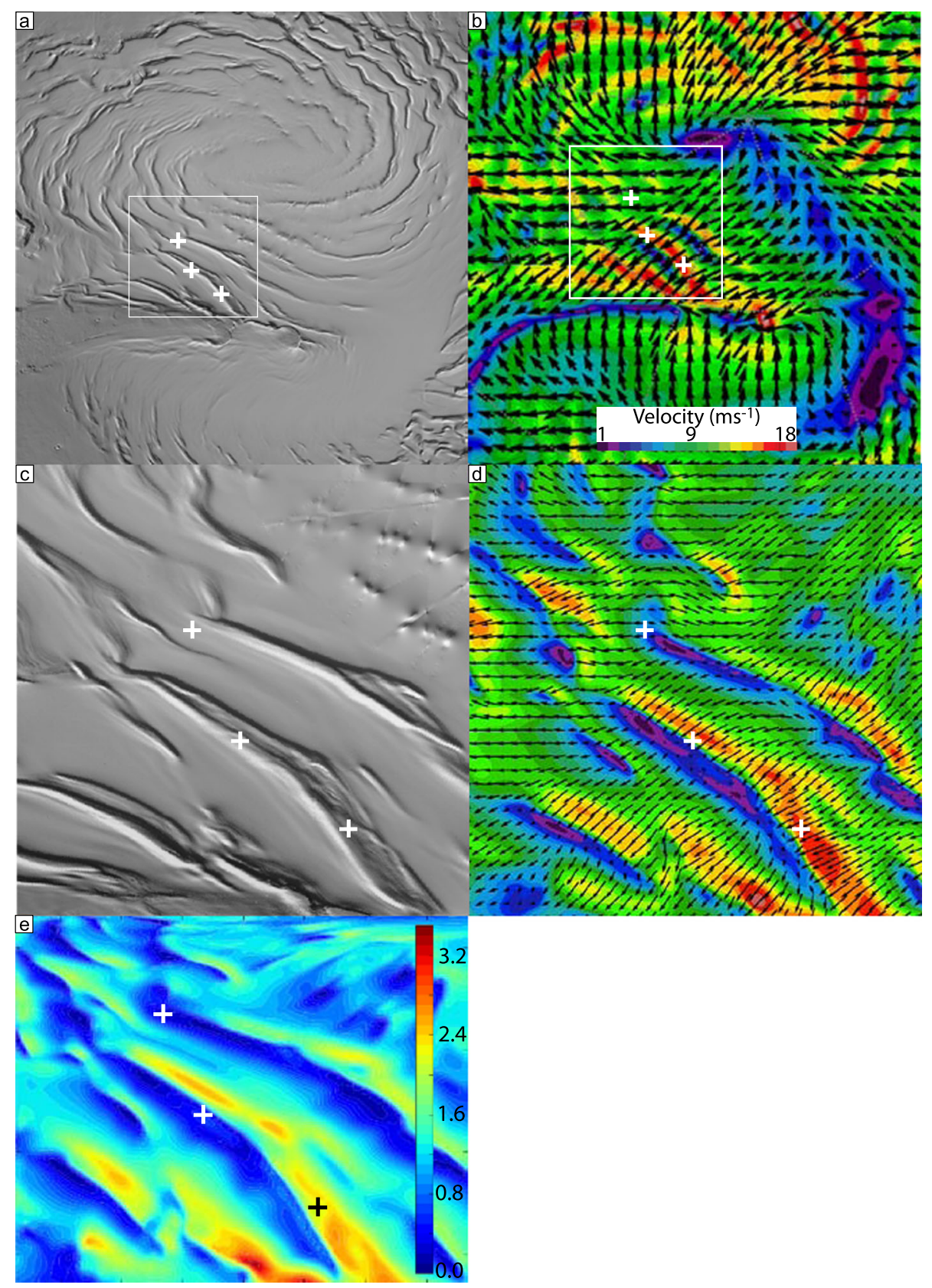

Figure 14. Locations and nested mesoscale model indicating velocities of katabatic winds on NPLD at $\mathrm{L}_{\mathrm{s}}$ 50. (a) MOLA-shaded topography of portion of NPLD corresponding to extent of mesoscale model Nest 2. (b) Nest 2 of mesoscale model with $6.7 \mathrm{~km}$ resolution per grid point. (c) Extent of mesoscale model Nest 3 in shaded relief. (d) Nest 3 with $2.2 \mathrm{~km}$ resolution. Winds $30 \mathrm{~m}$ above the surface reach speeds in excess of $18 \mathrm{~ms}^{-1}$ on the trough high side, locations associated with greatest removal of ice. Winds leaving the troughs on the low side are much slower, $1 \sim 3 \mathrm{~ms}^{-1}$ and are associated with areas of deposition. Color scale same for Figures 14b and 14d. Box in Figure 14a indicates extent of Figures 14c and 14d. (e) Map showing calculated Froude numbers for simulation Nest 3 corresponding to Figure $14 \mathrm{~d}$. Values vary from $\sim 0$ on the low side to $>3$ on the high side. Plus signs indicate the same location in each image.

in the flow to be carried past the system in the erosional case. The eroded material can be assumed to remain suspended load that is not redeposited after the hydraulic jump [Kostic et al., 2010]. As with the depositional cyclic steps, flume experiments [Brooks, 2001] and numerical models [Parker and Izumi, 2000] have verified these results for erosional steps in terrestrial environments. Because the flow characteristics are so similar, sediment supply is the primary difference between depositional and erosional cyclic steps.

\subsection{Trough Formation and Coriolis Forcing}

[54] The NPLD spiral troughs are primarily constructional features as evidenced by the radar stratigraphy [Smith and Holt, 2010]. We suggest that the same processes observed 


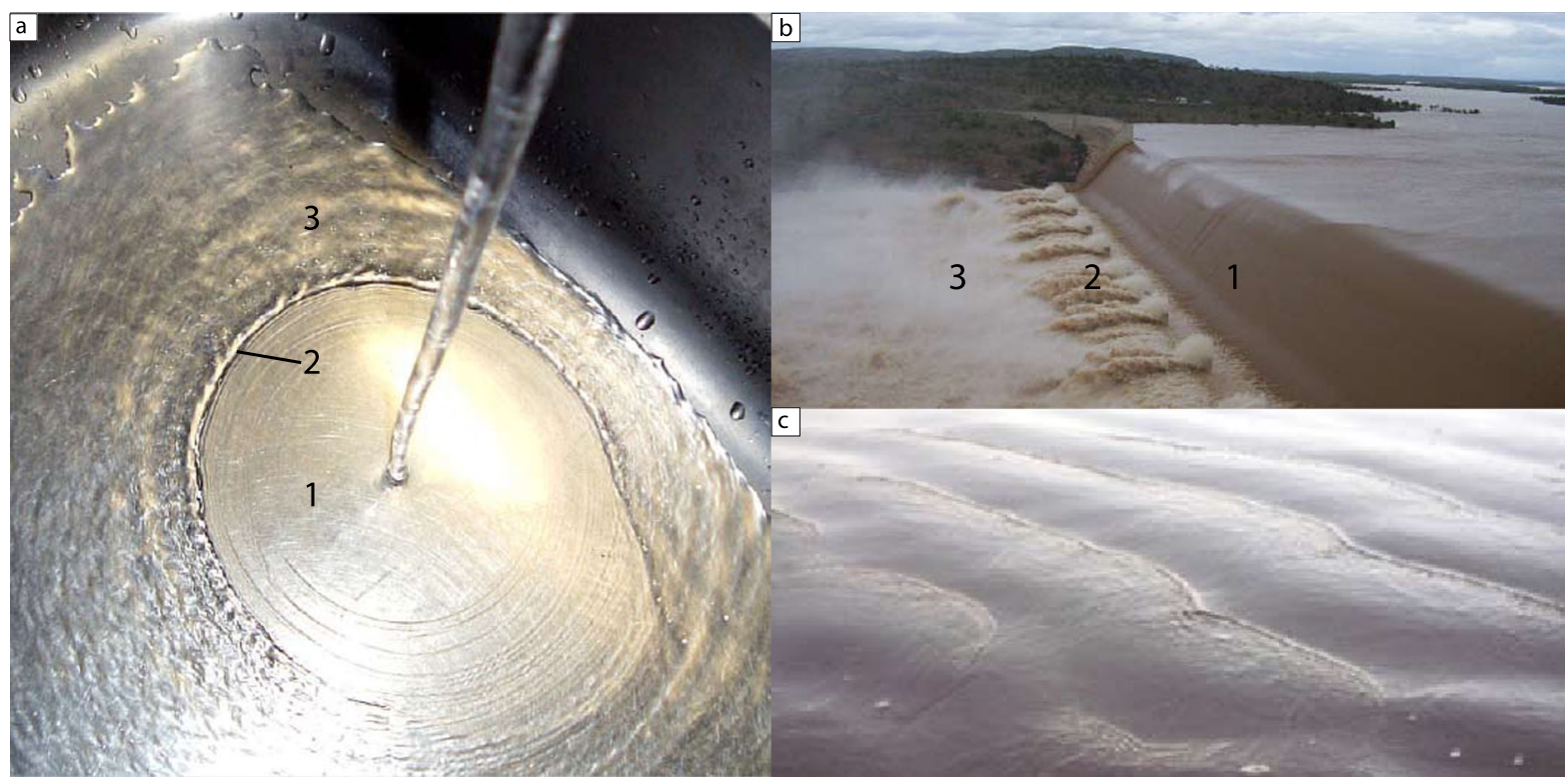

Figure 15. Terrestrial hydraulic jumps. (a) Hydraulic jump in a sink. Hydraulic jump forms even though there is no break in slope. (b) Hydraulic jump beneath Burdekin Dam, Australia. Engineers design rivers below dams to reduce energy by slowing water in hydraulic jumps. (1) Fast-moving water leaves the source. (2) A hydraulic jump appears when the flow becomes unstable. (3) Water depth increases and water flow rates decreases downstream of the hydraulic jump. Image uploaded by Thuringowacityrep at en. wikipedia. Permission is granted to copy, distribute, and/or modify this document under the terms of the GNU Free Documentation License Version 1.2. (c) Series of repeating hydraulic jumps during return of wave on a beach. The cyclic step model describes repeating hydraulic jumps to explain the repetition of steps and the pattern of erosion and deposition. Photo taken by I.B.S. at Tan Tan Plage, Morocco.

today were operating when the troughs formed. In particular, katabatic winds, jumps, and trough clouds existed at the time of onset. Prior to trough formation, NPLD topography was smoother than today [Smith and Holt, 2010; in preparation]. In flume experiments, cyclic steps and hydraulic jumps have been created on a smooth surface [Spinewine et al., 2009, Figure 5], much as the NPLD troughs may have began.

[55] A katabatic jump forms as a condition dictated by flow constraints; in particular, topography and atmospheric pressure are important. We propose that the effects of this jump are sufficient to make trough clouds, which in turn precipitate as snow or directly deposit the water vapor to the surface (Figure 16). Clouds typically form when either pressure increases or temperature decreases. Lied [1964] observed both of these qualities as he crossed the katabatic jump. Walking through the jump from downstream, he measured "a sudden drop in pressure and immediate rise in temperature." If the incoming winds are saturated or nearly saturated with water vapor, clouds will form as the pressure increases and temperature drops coming into the jump.

[56] Lied [1964] and Pettré and André [1991] detected a "wall of snow" at the site of a katabatic jump (Figure 13). If this snow reaches the surface, deposition occurs. This deposition of ice will eventually modify the topography to form a slope break that acts as a trigger for future katabatic jumps [Spinewine et al., 2009]. Thus, a topographic feedback mechanism exists to steepen topography. Once this feedback exists, the relatively quick onset and persistence of trough stratigraphy observed by radar [Smith and Holt, 2010] can be explained.
[57] Howard [2000] mapped the directions of wind streaks on the NPLD to determine wind vectors and found that the streaks align roughly perpendicular to the troughs. He concluded that topography is presently the primary influence on katabatic wind directions, with the Coriolis force exerting a secondary influence. This finding is in general agreement with our mesoscale modeling (Figure 14d). However, before the troughs formed, the NPLD was smoother [Smith and Holt, 2010]. At this time, local topographic control would be less significant, allowing the Coriolis force to be the primary influence on direction. Thus, during trough onset, katabatic jumps, which are themselves nearly perpendicular to the winds, would have a spiral pattern determined by Coriolis deflection of downhill flow.

[58] Smith and Holt [2010] observed that the NPLD spiral troughs are not all the same age, having formed on the NPLD at least twice. Surface age dates of the SPLD determined by crater counting statistics indicate that the troughs in the Southern Hemisphere are significantly older than even the oldest portion of the NPLD [Herkenhoff and Plaut, 2000]. This observation implies that conditions were favorable for spiral troughs to form during multiple periods in Mars' past. However, there is no evidence supporting the existence of troughs at the earliest stages of either pole. We propose two mechanisms to explain this.

[59] First, as with sediment waves and megadunes, the regional slope of the NPLD at the time of trough onset is a critical factor [Fahnestock et al., 2000; Smith and Holt, 2010]. Winds that flow down very shallow slopes will not become supercritical, precluding both katabatic jumps and 


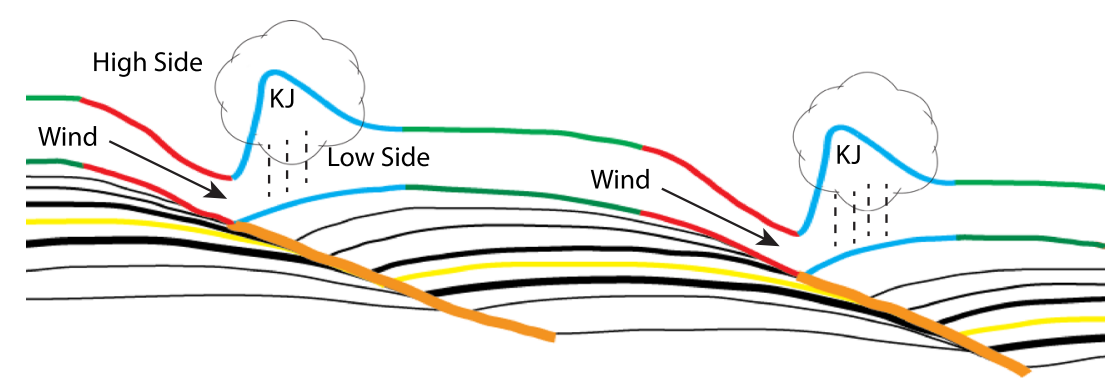

Figure 16. Cartoon depiction of cyclic steps. Wind enters the trough from the high side and accelerates downhill. Red indicates sublimation enhanced by wind. Flow depth increases quickly at site of katabatic jump, and deposition beneath a cloud as snow or frost begins (blue). Green indicates subcritical flow and no change in elevation. Yellow depicts one stratigraphic level in the section. Exposed layers on the high side (red) and mantling associated with deposition (blue) depict asymmetric accumulation as cause of migration.

significant wind-induced sublimation. Atmospheric changes could also contribute to the necessary conditions for trough formation. A recent study found large volumes of $\mathrm{CO}_{2}$ ice that were rapidly deposited and sequestered in the SPLD within the last several hundred thousand years [Phillips et al., 2011]. Prior to sequestration, the $\mathrm{CO}_{2}$ ice was most likely in the atmosphere, suggesting that the atmosphere and wind intensities could change during the lifetime of troughs.

\subsection{Exposures on Trough Walls, Asymmetric Accumulation, and Layer Offset}

[60] The contrast of the layer exposures and albedo on opposite trough walls can be directly attributed to cyclic step migration and katabatic jumps. As winds remove material from the trough high side, layers with high concentrations of dust are exposed [Massé et al., 2012]. Massé et al. [2012] found that greater than $80 \%$ ice is on the surface exterior to the trough, but the trough high side had as little $20 \%$ ice exposed beneath significant quantities of accumulated dust. Dust has a lower albedo than ice, so the combination of exposing dust and removing ice will decrease the overall albedo of the high side. Ice is removed in one of two ways, either by sublimation or mechanical transport, but dust is nonvolatile and only removed by mechanical transport during high intensity winds.

[61] On the opposite side of a trough, banded terrain overlies intertrough material. The combination of intermediate albedo and irregular mantling associated with banded terrain is explained by the recent deposition of ice and dust that has been transported from upstream. The intermediate albedo of banded terrain is then the result of strong mixing between ice and dust, which will produce an albedo between that of the constituents.

[62] Banded terrain is highly variable in albedo and location (Figure 1b). Pettré and André [1991] observed that katabatic jumps can move or migrate during a single storm and that they often have a different location during subsequent storms. They determined that the location of a katabatic jump is based on the incoming flow properties. Therefore, the multiple bands observed at many troughs (Figure 1b) may be the result of variable katabatic jump locations (Figure 8), due to variable winds.

[63] Two consequences of erosion and redeposition on the opposite trough walls are an asymmetric accumulation of ice and an offset of time-equivalent layers (yellow layers in
Figure 16). Howard et al. [1982] detected this asymmetry and offset with optical observations, and Smith and Holt [2010] confirmed it with radar. We propose that an alternating sequence of uniform deposition and transport created

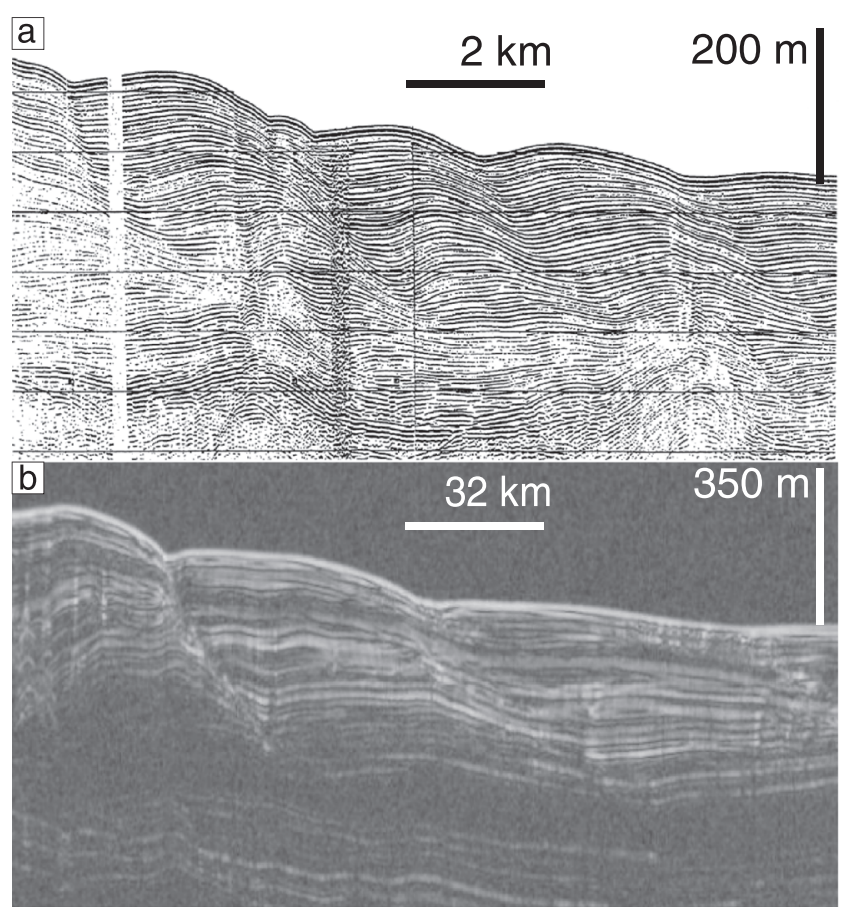

Figure 17. Stratigraphy of depositional cyclic steps. (a) Seismic image of sediment waves near continental slope at Var sedimentary ridge northwest of Italy (reproduced with permission from Migeon et al. [2000]). Layers are truncated in only a few spots, but upslope migration is clearly evident. Layer thickness variations are also readily apparent. (b) Portion of SHARAD radargram 598301 near spiral troughs on the NPLD. Displayed stratigraphy has similar patterns to submarine sediment waves in Figure 17a. The trough on the left has a well-delineated trough migration path, but the trough on the right looks more like a sediment wave. Different sublimation rates (possibly due to different wind speeds) on the high side may account for the contrast in stratigraphy. Location indicated in Figure 1a. 
the stratigraphy that is observed. Deposition occurs in the winter, when temperatures are low and a seasonal frost covers the surface. Winter deposition would act as a blanket that covers troughs entirely (time steps 1 and 3 in Figure 18). This is observed as a seasonal cap. Later, in spring, katabatic winds and trough clouds are active. They act to thin the new deposit on the high side (time steps 2 and 4 in Figure 18). Given sufficient transport, the original blanket of snow will become discontinuous and offset. Freshly exposed, older material on the high side is also ablated, resulting in migration but not thinning. Over repeated cycles of deposition and transport, the topography becomes amplified until reaching a steady state, as discussed in section 5.2.

[64] There is another hypothesis that can potentially explain the observations of asymmetric accumulation. Cold trapping of volatiles is known to occur on Mars at high latitudes due to lower temperatures [Clifford et al., 2000; Calvin and Titus, 2008] and on craters that receive nonuniform sunlight [Fishbaugh and Head, 2000]. It is therefore plausible that the spiral troughs act as insolationinduced cold traps and that the low-side deposits are primarily created by this mechanism, but two arguments counter that interpretation.

[65] First, accumulation on the low side, as predicted by cold trapping, should be found near the point of lowest temperature or where insolation is least. However, thickened deposits, as observed by SHARAD, extend well past the troughs and far into the intertrough region (Figure 2) [Smith and Holt, 2010, Figure 3]. The second point is related to albedo. Banded terrain has an intermediate albedo to dust and ice. Cold-trapped materials are purely volatile and should have the same albedo as ice. In a case of transport without wind, dust would remain on the high side, leaving a lag that covered layered terrain completely, and a pure ice deposit with high albedo at the cold-trap region. Both the observed extended deposits and intermediate albedo are inconsistent with the cold-trapping hypothesis. We find that invoking winds to transport the dust but not the ice is unnecessarily complicated and implausible. A much simpler explanation exists with the cyclic step model, which accounts for erosion on the high side and deposition on the low side by providing a mechanism of removal (wind transport) and deposition (snowfall or direct deposition) beneath the trough clouds.

\subsection{Slopes and Wavelength}

[66] The high-side slopes of troughs are uniformly steeper than those on the low side [Howard, 2000; Pathare and Paige, 2005]. As discussed above, differing processes affect each slope. Katabatic winds are fastest near the bottom of the trough, having had a longer distance to accelerate. $\mathrm{Ng}$ and Zuber [2006] found that in a katabatic wind regime, "the lower part of each scarp sublimates faster than the upper part." This is a consequence of faster winds than can accommodate higher vapor pressures and transfer more energy into the surface. The combination of increased capacity and enhanced sublimation makes the removal of material more likely. Over time, the high side tends to increase steepness, in turn accelerating winds to greater speeds, creating a positive feedback. However, in the seasons with sunlight, the lowest section of the equator-facing slopes remains in shadow for longer periods than the highest sections. Thus, throughout a Martian year, insolation-induced sublimation is greatest near the top of the trough wall, tending to reduce the slope. Insolation and wind-driven sublimation are therefore competing mechanisms, acting as a check to run away steepening from wind ablation.

[67] On the low side of the trough, there is no competing mechanism. Deposition from the cloud is predominantly at the trough bottom, near the katabatic jump, but takes some time to settle out. With weak low-side winds, the remaining snow will deposit downstream of the trough, thinning with increasing distance. This is substantiated by radar observations, which show the deposit to be thickest near the trough bottom and decrease with distance toward the low side (Figure 2) [Smith and Holt, 2010].

[68] Spiral troughs in different regions have different wavelengths, best demonstrated by the contrast between troughs just north of Chasma Boreale $\left(\sim 0^{\circ} \mathrm{E}\right)$ with characteristic wavelength $40-50 \mathrm{~km}$ and those near the margin at $90^{\circ} \mathrm{E}$ with wavelengths of 20 to $30 \mathrm{~km}$. Atmospheric modeling and flume experiments demonstrate that flows require some distance to accelerate and reach a supercritical state. That distance determines the position of the initial step. Given sufficient space to accelerate after a katabatic jump, the winds will form another, setting up a characteristic wavelength that continues until the regional slope changes or the edge of the ice cap is reached.

[69] The relationship between regional slope (the slope on which cyclic steps form) and wavelength is well understood [Sun and Parker, 2005] and testable in flume experiments [Yokokawa et al., 2009]. Steeper regional slopes favor shorter wavelengths. Therefore, the troughs north of Chasma Boreale, which began on a shallower regional slope than those at $90^{\circ} \mathrm{E}$, should have a longer wavelength. Smith and Holt (in prep) detect this wavelength / slope correlation. They find that troughs north of Chasma Boreale have the longest wavelength on the NPLD. These troughs formed on a surface with average regional slope $0.19^{\circ}$. East of that, near the margin at $90^{\circ} \mathrm{E}$, the troughs formed on a surface with average slope $0.32^{\circ}$. The troughs between $180^{\circ} \mathrm{E}$ and $270^{\circ} \mathrm{E}$ have a more variable but intermediate wavelength to the other two regions and are spaced between 30 and $40 \mathrm{~km}$ apart. Those troughs formed on a surface with average slope $\sim 0.27^{\circ}$.

\subsection{Migration of Spiral Troughs}

[70] Howard et al. [1982] were the first to suggest that winds were an important component in trough migration and provided predictions of 3-D stratigraphy that proved to be highly accurate. They described migration as the removal of material from the high side of a trough, as evidenced by wind streaks, and redeposition of the material on the low side. Howard and colleagues were fundamentally correct in their interpretation but did not have observations with high enough spatial or temporal resolution to observe active transport via winds. New, higher-resolution observations presented in this paper reveal that katabatic jumps provide the mechanism for alternating between accelerating and decelerating flow, or ablation and deposition.

[71] By analyzing SHARAD radar, Smith and Holt [2010] supported the conclusions of Howard et al. [1982] and demonstrated that the oldest of the NPLD troughs have undergone as much as $700 \mathrm{~m}$ of deposition since their formation and have migrated $\sim 50 \mathrm{~km}$ during that period. Smith and Holt [2010] isolated a bounding surface that traced the path 


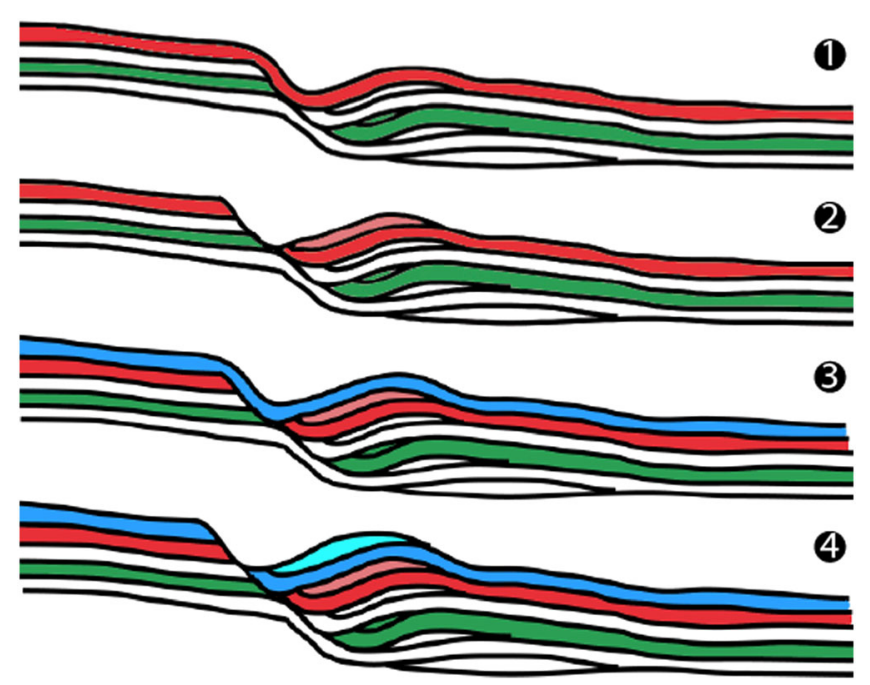

Figure 18. Cartoon of trough evolution. (1) A layer is deposited uniformly in winter (red). (2) Subsequent winds transport material from high side to low side of trough. High side is thinned as low side is thickened. (3) and (4) repeat (1) and (2). After many steps, a discontinuity will form where new layers onlap the eroded layers.

of migration through time for many troughs on the NPLD. The bounding surface varies in steepness, indicating variability in the ratio of accumulation to migration. We interpret this to mean that there is no short-term steady state for migration. Instead, it is likely that the NPLD troughs have undergone alternating regimes of net deposition and ablation throughout their history, with the long-term trend resulting in pronounced accumulation and migration.

[72] Not every trough on the NPLD behaves the same, however. Besides temporal variations, regional and local conditions affect each trough (Smith and Holt, in prep). Evidence for in situ trough ablation at one trough near $250^{\circ} \mathrm{E}$ suggests that some locations have experienced incision in the past [Rodriguez and Tanaka, 2011]. Smith and Holt (in prep) find that this trough currently experiences migration, but former conditions may have been similar to those on the SPLD, where erosional cyclic steps are more prominent.

[73] Overall, the SPLD troughs appear to behave differently than those on the NPLD. A test of the cyclic step model is to explain this discrepancy. Stratigraphic analysis from visible imagery suggests that a majority of troughs in the south formed during a period of ablation [Kolb and Tanaka, 2001], leaving no evidence for migration. Analysis of SHARAD radar images mostly agrees with that conclusion but finds a few locations exhibiting bounding surfaces and trough migration (supplementary section in Smith and Holt [2010]), adding to the puzzle. Thus, the majority of evidence supports the conclusion that at least some of the SPLD spiral troughs formed as erosional cyclic steps.

[74] Parker and Izumi [2000] explain that in erosional regimes sediment entering the hydraulic jump bypasses the step rather than being deposited. The NPLD and SPLD undergo the same processes in this scenario, but the incoming sediment (water vapor) supply determines if the low side of a trough will experience accumulation (i.e., there is no deposition because ice crystals within clouds are not sufficiently large to reach the ground, therefore bypassing the katabatic jump.) Different dust concentration, temperatures, and pressures on the SPLD potentially explain this difference.

[75] As with the north, the SPLD scenario is not uniform across the cap. At lower elevations on the SPLD, scalloped terrain exhibits a radar signature of asymmetric accumulation similar to the northern spiral troughs [Grima et al., 2011]. In addition, clouds associated with katabatic jumps are found in the scalloped terrain (Figure 11b). The combination of stratigraphy and presence of clouds suggests the likelihood of redeposition of ice and migration.

[76] Trough clouds are also observed at higher latitudes/ elevations on the SPLD (Figure 11a), with the possibility of redeposition. An explanation for the discrepancy between interpreted stratigraphy of Kolb and Tanaka [2001] and the implications with observed clouds is not readably available, but it is possible that regional and temporal differences, like those on the NPLD, contribute to the variations observed on the SPLD.

\subsection{Undulations}

[77] Various hypotheses have attempted to explain the origin of topographic undulations (Figure 3): viscous relaxation of troughs [Pathare and Paige, 2005], remnants of trough migration [Squyres, 1979], and the result of ice cap advance and retreat [Cutts et al., 1979]. The hypothesis that most closely approximates findings in this paper is one of standing waves emanating from the troughs [Howard, 2000]. Undulations share a stratigraphic relationship with the troughs. It is, therefore, clear that undulations must be explained in the context of katabatic winds, but cyclic step literature does not describe topographic undulations or hydraulic undular jumps.

[78] We agree in principle with the explanation of Howard [2000]. Observations presented in earlier sections demonstrate that some trough clouds have undular characteristics (Figures 4c, 5b, 6a, 8, and 11b). Frequently, the wavelengths and locations of these undular jumps match those of topographic undulations. Thus, it is plausible that undular jumps and clouds act as standing waves to deposit and create undular topography. While the cyclic step model does not directly predict the existence of topographic undulations downstream of troughs, the flow regime and undular clouds are consistent with depositional processes required to maintain the undulations.

\subsection{Comparison of Cyclic Steps With Previous Models}

[79] The debate surrounding spiral troughs is primarily due to their complex structure and many unique features. In the previous sections, we discussed 10 qualities that are integral to understanding trough evolution. Therefore, we propose a list of 10 criteria that any trough formation and evolution hypothesis should address: (1) trough initiation, (2) largescale spirals that have opposite sense in the Northern and Southern Hemispheres (Figure 1) [Cutts, 1973], (3) ablation of the equator-facing walls, exposing low-albedo layers [Warner and Farmer 2008], (4) mantling deposits with intermediate albedo on the poleward slopes [Howard et al., 1982], (5) offset layering as detected by SHARAD [Smith and Holt, 2010], (6) asymmetric accumulation of ice across the troughs (Figure 2) [Smith and Holt, 2010], (7) equatorfacing slopes that are uniformly steeper than pole-facing 
slopes [Pathare and Paige, 2005], (8) different trough wavelengths occurring in different regions [Pathare and Paige, 2005; Smith and Holt, in prep], (9) migration of the NPLD troughs as revealed by SHARAD [Smith and Holt, 2010], and (10) purported lack of trough migration on the SPLD [Kolb and Tanaka, 2001]. Additionally, two other observations indirectly related to the troughs should be explained: the troughs formed after $1 / 2-2 / 3$ of the NPLD were deposited [Smith and Holt, 2010; Smith and Holt, in prep], and the relationship of low-amplitude undulations to the spiral troughs. While many of the previous models provided mechanisms of formation or even predicted migration, they do not offer the same robustness in matching all of the criteria as the cyclic step model. Primarily, most models of trough formation cannot account for evidence of asymmetric accumulation, offset layering, or late onset, and the simplest models can only meet two or three of the criteria.

[80] Ivanov and Muhleman [2000] used albedo contrasts to explain trough formation due to sublimation. They found that trough walls with low albedo should sublime faster than the surrounding intertrough regions. While this is most certainly true, it only accounts for formation and ablation of the equator-facing walls. Their model did predict slope asymmetries, although they were underestimated. They could not explain spirals or the onset of troughs midway through NPLD development. In this way, they met criteria $1,3,7$, and 10 .

[81] Another hypothesis proposed that lateral heat diffusion was the mechanism by which troughs formed [Pelletier, 2004]. This model predicted a spiral pattern for the troughs but was unsuccessful in explaining why the NPLD troughs would have opposing sense from the SPLD troughs. Related to stratigraphy, only the exposure of layers on the high side could be explained. Criteria 1 and 3 and part of criterion 2 were met in this model.

[82] In situ erosion from wind was another proposed model for formation [Kolb and Tanaka, 2001; Rodriguez and Tanaka, 2011]. These models could employ the Coriolis force to explain the spirals, and winds could remove ice to form the troughs, but the resulting stratigraphy did not match NPLD troughs [Smith and Holt, 2010, Figure 3a]. Smith and Holt [2010] discussed the stratigraphy observed with SHARAD and found it completely incompatible with in situ erosion, which only accommodates criteria 1, 2, 3, and 10. It cannot explain the wavelength differences between regions, asymmetric accumulation, or migration of the NPLD troughs.

[83] Some models did not have formation mechanisms but were more successful at predicting the stratigraphy [Squyres, 1979]. Squyres [1979] used the observations of exposed layered terrain on the high side and no exposures on the low side to predict a stratigraphy that was the result of migration. While this model included migration and ablation of the high side, it did not provide a formation mechanism or explain the spirals nor could this model explain thickened deposits on the low side of troughs (Figure 10 of that paper) as detected by SHARAD [Smith and Holt, 2010, Figures 3e and 3f]. Alone, only Criteria 3, 5, and 9 were met. However, in combination with the formation mechanisms of Ivanov and Muhleman [2000] or Pelletier [2004], criteria 1 or 2 could be added. As a caveat, there is significant variation in NPLD trough stratigraphy, and some troughs do have reduced asymmetry (Smith and Holt, in prep). While this supports the model of Squyres [1979] and the conclusion that the troughs undergo variable amounts of migration due to wind and insolation, these examples do not represent the entire family of troughs.

[84] Other models based on flowing ice predicted that given enough stress (and Coriolis forcing), the ice would fracture [Weijermars, 1986; Zeng et al., 2008]. These models offered a formation mechanism and proposed a method by which the troughs would spiral. Heuristically, these models may also account for the exposed layers on the high side and offset of layering observed. However, neither banded terrain nor asymmetric accumulation is explained. Also, these models relied on basal sliding and could not explain why the "fractures" would only extend part way through the ice. Only Criteria 1, 2, 3, 5, and 10 are met.

[85] Ng and Zuber [2006] expounded on the Squyres [1979] model and offered several benefits over previous ideas. They explained that the spiral pattern was the result of Coriolis-directed winds and gave a plausible mechanism of formation. They argued that winds were important for bringing in low-albedo dust and depositing it in a spiral pattern. Once the dust was on the surface, preferential sublimation would occur where the albedo had been affected. Thus, spiral depressions would form due to sublimation on the surface where dust is thickest. Over time, the depressions would become troughs. Their model combined the formation due to sublimation of Ivanov and Muhleman [2000] with the migration due to sublimation of Squyres [1979]. Additionally, they loosely employed instabilities in the wind to explain the different wavelengths in different regions, and indirectly, they could accommodate slope asymmetries. In this way, they were able to create a scenario by which criteria $1,2,3,5,7,8$, and 9 were met. However, like Squyres [1979], they did not predict thickened low-side deposits nor could they account for intermediate albedo banded terrain, late onset, or SPLD stationary troughs.

[86] Thus, the model of $\mathrm{Ng}$ and Zuber [2006] was very successful in explaining a majority of observations related to troughs. However, $\mathrm{Ng}$ and Zuber [2006] had not observed their primary mechanism of formation: evidence of dust transport near the troughs. Detections of "dust storms" by Warner and Farmer [2008] might have provided that mechanism. Warner and Farmer [2008] interpret clouds near the troughs as removal of dust from the high side and likened this to the transport of material by winds. Their Figure 16 even had linear streaks near the high side to support their interpretation. They inferred the dust was being removed from the base of the equator-facing scarps and depositing it in the intertrough region. This would account for banded terrain on the low side. Unfortunately, the marriage of $\mathrm{Ng}$ and Zuber's [2006] model with Warner and Farmer's [2008] observations is not successful. The removal of dust from a trough is incompatible with dust being required to form a trough, and in this scenario, banded terrain would begin to form a second trough. To make this marriage successful, processes present today would have to be different from those that were present when the troughs formed. Furthermore, the discrepancy of north and south polar troughs and asymmetric accumulation must be addressed.

[87] Finally, we base many of our 10 criteria on the observations of Howard et al. [1982], Howard [2000], and Smith 
Table 2. Values Used as Inputs Into Equations in This Study ${ }^{\mathrm{a}}$

\begin{tabular}{lcc}
\hline$\rho_{1}\left(\mathrm{~g} / \mathrm{cm}^{3}\right)$ & Ice & 916 \\
$\rho_{2}\left(\mathrm{~g} / \mathrm{cm}^{3}\right)$ & Laden Air & 0.0250 \\
$\rho_{3}\left(\mathrm{~g} / \mathrm{cm}^{3}\right)$ & Ambient Air & 0.0247 \\
\hline & Supercritical & Subcritical \\
$F r$ & 5 & 0.31 \\
$U$ & 18 & 3 \\
$g$ & 3.72 & 3.72 \\
$h$ & 200 & 1318 \\
$C$ & $9.8 \mathrm{E}-08$ & $8.9 \mathrm{E}-08$ \\
Flux & $3.5 \mathrm{E}-04$ & $3.5 \mathrm{E}-04$ \\
\hline & Low Estimate & High Estimate \\
$F r_{1}$ & 1.7 & 5 \\
$F r_{2}$ & 0.1 & 0.9 \\
$\mathrm{U}$ & 14 & 20 \\
$h_{1}$ & 150 & 250 \\
$h_{2}$ & 400 & 1300 \\
\hline
\end{tabular}

${ }^{a}$ Densities of laden air and ambient air are taken from Mars Climate Database web interface (C) LMD/OU/IAA/ESA/CNES [http://www-mars. lmd.jussieu.fr/mars/access.html]. Lower Froude numbers are estimated from the existence of undular clouds, and higher Froude numbers are estimated from the mesoscale atmospheric model. Flow velocities are taken from the atmospheric model. $h_{1}$ is estimated from Figure 7 , and $h_{2}$ is from the Bélanger Equation (equation (4)). Concentration and flux are calculated from equations (5) and (6), respectively.

and Holt [2010]. We believe that the stratigraphy they observe is of critical importance in understanding trough evolution. Any model of formation that does not account for offset, asymmetric layering, or late onset has not successfully described the troughs. The observations of Howard et al. [1982] and Smith and Holt [2010] demonstrated that the troughs were migrating as the result of transport from winds, but they had not yet explained the acceleration and deceleration associated with erosion and deposition. Furthermore, their hypothetical cross sections predicted the correct stratigraphy, but their processes were not sufficient to explain trough formation. It is only with the inclusion of repeating katabatic jumps in the depositional (NPLD) or erosional (SPLD) cyclic steps model that criteria 1, 2, 3, 4, 5, 6, 7, 8,9 , and 10 can be met. Furthermore, undular jumps also offer an explanation for the undulations that are observed downstream from troughs. Finally, stratigraphic evidence for migrating troughs does not extend to the lowest portion of the polar layered deposits. A wind regime that changes periodically can account for the onset of troughs midway through NPLD development.

\section{Estimation of Rates}

\subsection{Calculation of Concentration and Flux}

[88] Here we use two distinct methods to obtain the order of magnitude of flux of $\mathrm{H}_{2} \mathrm{O}$ across the katabatic jump. These preliminary estimates will need to be refined in future work through either mesoscale meteorological modeling or high-resolution multispectral imagery.

[89] The first method is to employ Froude analysis based on previous observations. Solving for the volumetric concentration of $\mathrm{H}_{2} \mathrm{O}$ within the high-side wind requires substituting equation (3) into equation (2) and reducing terms.

$$
C=\frac{\frac{U^{2} \cdot \rho_{3}}{F r_{d}^{2} \cdot g \cdot h_{1}}-\left(\rho_{2}-\rho_{3}\right)}{\rho_{1}-\rho_{3}}
$$

[90] The $\mathrm{H}_{2} \mathrm{O}$ concentration within the katabatic winds descending into a trough with parameters listed in Table 2 is $\sim 1 \times 10^{-7} \mathrm{~m}^{3} / \mathrm{m}^{3}\left(9 \times 10^{-3} \mathrm{~mol} \mathrm{H} \mathrm{H}_{2} \mathrm{O} / \mathrm{mol}\right.$ air; we use both units for comparison in the rest of the paper). The calculated concentration represents the total amount of $\mathrm{H}_{2} \mathrm{O}$ in the highside flow. This value is highly sensitive to specific inputs: for example, the ratio of velocity to densimetric Froude number is squared.

[91] In terrestrial flows, deceleration is associated with deposition. Particles carried by air or water are often at the threshold of suspension. As the flow slows down, it can no longer carry those particles, and they precipitate. We use this analogy to define the transition from net ablation to net deposition as the boundary of rapid deceleration or the katabatic jump. Creating this boundary enables the estimate of $\mathrm{H}_{2} \mathrm{O}$ concentration below the jump. Equation (6) calculates the flux, $\Phi$, across this boundary [Ball, 1956].

$$
\Phi=U_{1} \cdot h_{1} \cdot C_{1}=U_{2} \cdot h_{2} \cdot C_{2}
$$

[92] Conservation requires that flux of particles entering the boundary must equal the flux of particles leaving it, $\sim 3.6 \times 10^{-4} \mathrm{~m}^{2} \mathrm{~s}^{-1} \mathrm{~mol} / \mathrm{mol}$. Low-side flow depth was estimated from equation (4) to be $\sim 1300 \mathrm{~m}$. Using $4 \mathrm{~ms}^{-1}$, a velocity consistent with estimates from Spiga et al. [2011] and section $\mathbf{4}$ of this paper, the post hydraulic jump concentration of water molecules is $\sim 7 \times 10^{-8} \mathrm{~m}^{3} / \mathrm{m}^{3}\left(5.5 \times 10^{-3} \mathrm{~mol} / \mathrm{mol}\right)$, $\sim 0.7$ times the value prejump.

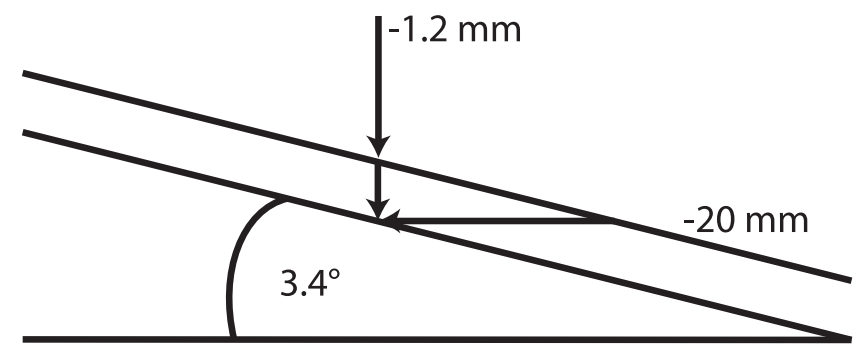

Figure 19. Cartoon depicting geometry of trough high-side erosion. Conservative estimates of migration are one $10 \mathrm{~h}$ wind event per year. During that time, $\sim 1.2 \mathrm{~mm}$ of ice is removed from the high side. On a slope of $3.4^{\circ}$, this equates to $\sim 20 \mathrm{~mm}$ scarp retreat or migration per year. Faster winds or longer durations will increase the migration rate. 

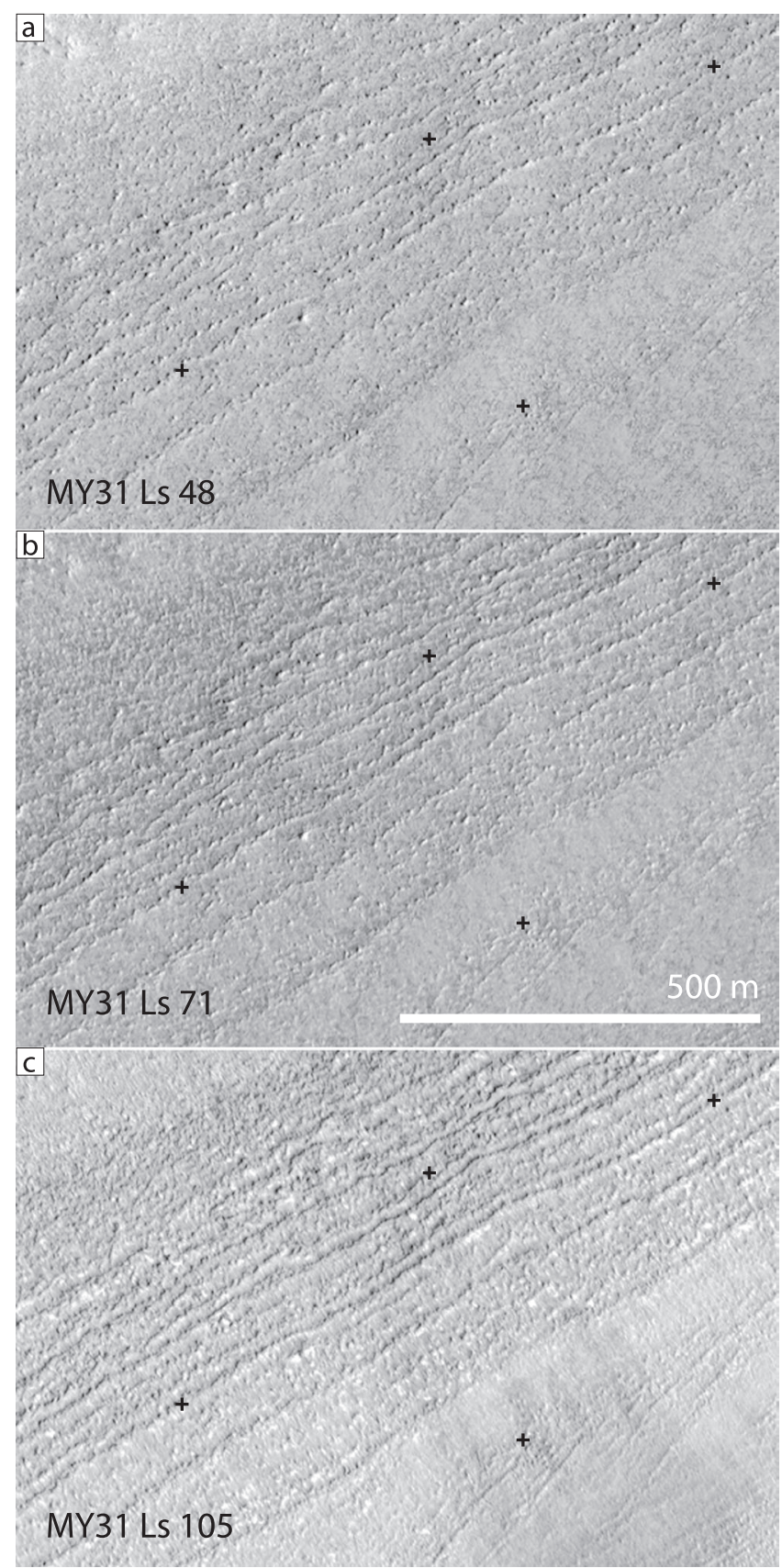

Figure 20. HiRISE images detect enhanced surface texture on the high side of a trough during katabatic wind season. (a) ESP_027056_2670 taken during Mars year 31 at $\mathrm{L}_{\mathrm{s}} 48$, prior to katabatic wind season. Surface has subdued texture, and no wind streaks are present. (b) ESP_026054_2670 taken during Mars year 31 at $\mathrm{L}_{\mathrm{s}} 71$, before peak of katabatic wind season. Little change is observed from earlier image. (c) ESP_025368_2670 taken during Mars year 31 at $\mathrm{L}_{\mathrm{s}} 105$, soon after katabatic wind season. Trough high-side slope has visible wind streaks and enhanced surface texture, consistent with the removal of a mantling surface layer. All images were taken at the same emission angle to reduce parallax. Location indicated by star in Figure 1a.
[93] As a first test to the cyclic step model, we apply the low-side calculated values to equations (2) and (3) to determine the densimetric Froude number below the hydraulic jump. The result, $\sim 0.45$, is consistent with the range of published Froude numbers below terrestrial hydraulic jumps with two-phase flow [e.g., Kostic et al., 2010], supporting the framework for this estimation.

[94] Our second method for estimating water-ice concentration in a katabatic jump takes advantage of the fact that in many cases, visible trough clouds are associated with this phenomenon. Since the clouds appear optically thick in THEMIS images (Figures 4c, 6, and 8), we assume that their optical depth is at least 1. From this, we are able to obtain an order of magnitude of the quantity of water/ice within such a cloud (Spiga and Forget [2009], see formula in the caption of Figure 10).

[95] We assume the size of ice particles is about $10 \mu \mathrm{m}$ (a conservative estimate between the common size encountered in Martian water-ice clouds [Madeleine et al., 2012] and the fast-falling ice particles detected by Whiteway et al. [2009]). We also assume that the extinction coefficient is $\sim 2$. The vertical extent of trough clouds is probably around $200 \mathrm{~m}$ given the depth of the katabatic layer. This yields a mass mixing ratio for water/ice within the trough clouds of about $2 \times 10^{-3} \mathrm{~kg} / \mathrm{kg}$ or a volumetric mixing ratio of about $5 \times 10^{-3} \mathrm{~mol} / \mathrm{mol}$ and corresponds to a total mass of ice particles within trough clouds of $\sim 7$ precipitable microns ( or $\sim 7 \times 10^{-3} \mathrm{~kg} \mathrm{~m}^{-2}$ ). The concentration calculated in this way provides a check for $\mathrm{H}_{2} \mathrm{O}$ concentrations calculated by the first method. Not all of the ice will reach the ground, but only the flux of $\mathrm{H}_{2} \mathrm{O}$ across the katabatic jump is required for further calculations.

[96] Pathare and Paige [2005] found a conservative estimate of sublimation over the entire NPLD at 190 precipitable microns per year. This number is a cap-wide average and should be considerably higher over the low-albedo spiral troughs than the intertrough regions. Nevertheless, it is about 27 times what we find necessary for an optically thick cloud to form. Therefore, we find it reasonable that very powerful winds acting over a short time can contribute to the annual sublimation by a factor of $1 / 27$ or $\sim 4 \%$. If annual sublimation estimates were available for the spiral troughs, the percentage would certainly go down.

[97] It is important to note that the equations in this section are highly sensitive to input parameters. Our parameters were chosen to be conservative estimates, therefore choosing a cloud optical depth greater than 1 or a slightly higher velocity in equation (5) (both possible scenarios) results in a much greater concentration of $\mathrm{H}_{2} \mathrm{O}$ and thus a greater flux across the katabatic jump.

\subsection{Migration and Accumulation Rates}

[98] In order to estimate the total amount of water mass that crosses a hydraulic jump, we multiply the flux with the duration derived earlier. A $13 \mathrm{~m}^{3} / \mathrm{m}$ of ice along a flow path is transported during a storm of $10 \mathrm{~h}$. Assuming a high-side slope of length $11 \mathrm{~km}$ [Pathare and Paige, 2005] yields $1.2 \mathrm{~mm}$ of ablation along that slope (Figure 19). Over an area $25 \mathrm{~km}$ wide (approximate extent of trough cloud in Figure 5b), the volume of ice that passes through the hydraulic jump is $3 \times 10^{5} \mathrm{~m}^{3}$. Assuming no porosity, the mass of that much ice is $3 \times 10^{8} \mathrm{~kg}$. These 
numbers seem quite large, but over an area of greater than $300 \mathrm{~km}^{2}$, it represents only $1 \mathrm{~mm}$ of ablation, quite a small amount. HiRISE detects surface changes during the katabatic wind season (Figure 20). Noticeable in Figure 20 is a marked increase in surface texture on the trough high side. One millimeter of erosion should not be detectible with the $25 \mathrm{~cm}$ resolution of HiRISE. Thus, we infer either that more than $1 \mathrm{~mm}$ of material is eroded or enhanced surface texture reveals nonuniform ablation with some parts experiencing no erosion while others experience more, for an average of $1 \mathrm{~mm}$.

[99] The slope of the high side must be considered in order to estimate scarp retreat during any given storm. Using data from the Mars Orbiter Laser Altimeter (MOLA) [Smith et al., 2001], Pathare and Paige [2005] measured a range of high-side slopes on interior troughs between $2.0^{\circ}$ and $14.5^{\circ}$. The slopes for their $\mathrm{H} 2$ and $\mathrm{H} 3$ troughs (shown in Figure 6C) are 3.1 and $3.4^{\circ}$, respectively. Adopting $3.4^{\circ}$, and assuming the entire $11 \mathrm{~km}$ slope eroded uniformly, the high-side slope retreats $20 \mathrm{~mm}$ (Figure 19). Since we assume only one $10 \mathrm{~h}$ jump event per year as determined in section 4.4, we find an annual migration rate for polar troughs of about $20 \mathrm{~mm}$ per year.

[100] Smith and Holt [2010] used SHARAD reflectors to measure $\sim 50 \mathrm{~km}$ of horizontal trough migration at the $\mathrm{H} 2$ and H3 troughs of Pathare and Paige [2005]. The time required to migrate $50 \mathrm{~km}$ at $20 \mathrm{~mm}$ per year is $\sim 2.5 \times 10^{6}$ Mars or $\sim 4.7 \times 10^{6}$ Earth years. Hence, the age of the spiral troughs determined by this analysis is greater than the estimated age of the NPLD, $\sim \times 10^{6}$ Earth years [Levrard et al., 2007]. Based on ice accumulation rates and depth of initiation, the troughs were estimated to have formed between $5 \times 10^{5}$ and $2.5 \times 10^{6}$ Earth years ago [Smith and Holt, 2010], a factor between 2 and 10 younger than our estimate.

[101] Our calculations are made in the context of the cyclic step model: We made the implicit assumption that trough migration is due entirely to katabatic wind transport and ignored other processes. Previous studies have determined that in addition to winds, insolation would remove ice from the high-side slope [Howard, 2000]. Hence, high-side migration will be supplemented during the summer season, when temperatures are warmer. Our constraints in this study are not precise enough to determine exactly how much migration is due to wind or sun; yet, our estimates tend to show that wind transport played a major role in the history of migration of polar troughs.

[102] Nevertheless, there are factors in our calculations that can greatly modify the migration rate (and thus, age of the troughs) in order to find younger ages. The best constraints available from radar, imagery, and atmospheric models have been used for these analyses, but the chosen inputs may be altered within the modeled and observed limits. For example, if we assume two katabatic jump events per year instead of one, we obtain an age consistent with previous estimates. Likewise, another factor requires only a slight adjustment; changing the wind speed in equation (5) from 18 to $20 \mathrm{~m} / \mathrm{s}$ more than doubles the $\mathrm{H}_{2} \mathrm{O}$ concentration, resulting in a trough age of $2 \times 10^{6}$ Earth years.

[103] Finally, if we apply the ratio of migration to accumulation as determined by Smith and Holt [2010] to our wind-only model, we find that between 0.22 and $0.28 \mathrm{~mm}$ of ice per Mars year (or 0.12-0.15 mm per Earth year) accumulated since the troughs initiated. This number is lower than published accumulation estimates of between 0.28 and $1.2 \mathrm{~mm} / \mathrm{yr}$ [Herkenhoff and Plaut, 2000; Fishbaugh and Hvidberg, 2006] but is within a factor of 2 to the lower estimate, reconcilable with a slightly higher migration rate.

\section{Conclusions}

[104] Any hypothesis that attempts to describe the formation and evolution of spiral troughs of the Martian polar layered deposits must be able to explain all of the available qualities related to their morphology and stratigraphy. To date, no model has successfully accounted for all of the trough features. The cyclic step model meets these criteria and is especially compelling because a katabatic jump explains all atmospheric and stratigraphic observations of a single trough, and repeating katabatic jumps deflected by the Coriolis force accounts for the gross spacing and orientation of the troughs. This model is also supported by observations of active processes and meteorological modeling.

[105] The cyclic step model outlined by Parker [1996] provides the foundation for explaining all 10 of the following criteria: (1) formation mechanism, (2) large-scale spirals that have opposite sense in opposite hemispheres [Cutts, 1973], (3) ablation of the equator-facing walls exposing low-albedo layered terrain [Warner and Farmer 2008], (4) irregular mantling of "banded terrain" material, with intermediate albedo on pole-facing slopes [Howard et al., 1982], (5) offset layering as detected by SHARAD [Smith and Holt, 2010], (6) asymmetric accumulation of ice across the trough [Smith and Holt, 2010], (7) larger surface slopes on the equator-facing walls than on the pole-facing walls [Pathare and Paige, 2005], (8) different trough wavelengths in different regions on the NPLD [Pathare and Paige, 2005; Smith and Holt, in prep], (9) migration of the NPLD troughs [Smith and Holt, 2010], and (10) apparent lack of trough migration on the SPLD [Kolb and Tanaka, 2001]. Furthermore, we find that the topographic undulations discussed by Cutts et al. [1979] can be linked to spiral trough formation and trough clouds.

[106] Because these features match predictions so well, it is possible to use flow modeling related to the Froude number to describe the conditions at the NPLD and to derive order of magnitude analytical solutions for migration and accumulation rates. While highly dependent on input parameters and qualified assumptions, these analyses represent a new method for estimating migration of troughs and accumulation of ice at the NPLD, independent of previous methods based on assumed accumulation rates. Using discussed constraints, we calculate an annual migration rate directly related to winds of $\sim 20 \mathrm{~mm}$ per year and an average ice accumulation of $0.12-0.15 \mathrm{~mm}$ per Earth year. When better data, the inclusion of insolation, or improved models are available, this framework can be easily adapted to include up-to-date analysis.

[107] Furthermore, this model is testable on the decadal time scale. Observations from the highest resolution visible instrument, HiRISE, can observe at the submeter scale. Therefore, detecting elevation changes in areas of high activity may be a reality over just a few years. During that time, the monitoring of Aeolian activity and surface changes will continue. With future observations, we will be able to increase the reliability of the estimates contained in this paper.

[108] Our investigations provide a significant step to understanding the processes that control spiral trough formation and 
evolution, but there remains much work to do, such as a broader SHARAD survey to detect variability of troughs in more locations (Smith and Holt, in prep). Besides finding images of trough clouds in coming years and higher-resolution atmospheric modeling, there are remaining questions to be addressed. What is the contribution of sublimation from insolation on the high side? Can we better understand the relationship between katabatic jumps and the formation of trough clouds? What physical conditions are met for the clouds to form? Lastly, can we differentiate between snowfall and frost buildup on the trough low side? These questions will all be addressable in detail in future investigations when more data are available.

[109] A challenge for the future is the development of a numerical model of cyclic steps on Mars that (a) explains their initiation as a stability problem and (b) predicts the spiral troughs observed on Mars. This model will have to take into account the Coriolis force, along with the mechanisms that give birth to jumps within the katabatic flow. It should also describe sublimation and deposition of ice rather than erosion and deposition of sediment. We believe that such a model is within reach.

[110] Acknowledgments. This work was supported by NASA ESSF Fellowship NNX10AT24H, NASA MDAP grant NNX10AO26G, and the Jackson School of Geosciences. The first author kindly thanks Le Laboratoire de Météorologie Dynamique for hosting him during the writing and development of this manuscript. Arizona State University's JMARS program and Web-based Mars Image Explorer were instrumental in conducting the survey of THEMIS images.

\section{References}

Andersen, V. M. (1978), Undular hydraulic jump, J. Hydraul. Div., 104(8), $1185-1188$.

Ball, F. K. (1956), The theory of strong katabatic winds, Aust. J. Phys., 9(3), 373-386.

Ball, F. K. (1957), The katabatic winds of Adélie Land and King George V Land, Tellus, 9(2), 201-208.

Brooks, P. C. (2001), Experimental study of erosional cyclic steps, University of Minnesota.

Calvin, W. M., and T. N. Titus (2008), Summer season variability of the north residual cap of Mars as observed by the Mars Global Surveyor Thermal Emission Spectrometer (MGS-TES), Planet. Space Sci., 56(2), 212-226, doi:10.1016/j.pss.2007.08.005.

Christensen, P. R., et al. (2004), The Thermal Emission Imaging System (THEMIS) for the Mars 2001 Odyssey Mission, Space Sci. Rev., 110(1/2), 85-130, doi:10.1023/B:SPAC.0000021008.16305.94.

Christian, S., J. W. Holt, S. Byrne, and K. E. Fishbaugh (2013), Integrating Radar stratigraphy with high resolution visible stratigraphy of the north polar layered deposits, Mars, Icarus, doi:10.1016/j.icarus.2013.07.003.

Clifford, S. M., et al. (2000), The state and future of Mars polar science and exploration, Icarus, 144(2), 210-242.

Cutts, J. A. (1973), Wind erosion in the Martian polar region, J. Geophys. Res., 78(20), 4211-4221.

Cutts, J. A., and B. H. Lewis (1982), Models of climate cycles recorded in Martian polar layered deposits, Icarus, 50(2-3), 216-244.

Cutts, J., K. Blasius, G. Briggs, M. Carr, R. Greeley, and H. Masursky (1976), North polar region of Mars: Imaging results from Viking 2, Science, 194(4271), 1329-1337.

Cutts, J., K. Blasius, and W. Roberts (1979), Evolution of Martian polar landscapes: Interplay of long-term variations in perennial ice cover and dust storm intensity, J. Geophys. Res., 84(B6), 2975-2994.

Fahnestock, M. A., T. A. Scambos, C. A. Shuman, R. J. Arthern, D. P. Winebrenner, and R. Kwok (2000), Snow megadune fields on the East Antarctic Plateau: Extreme atmosphere-ice interaction, Geophys. Res. Lett., 27(22), 3719-3722.

Fedele, J. J., and M. H. García (2009), Laboratory experiments on the formation of subaqueous depositional gullies by turbidity currents, Mar. Geol., $258(1-4), 48-59$.

Fildani, A., W. R. Normark, W. R. Kostic, and G. Parker (2006), Channel formation by flow stripping: Large-scale scour features along the
Monterey East Channel and their relation to sediment waves, Sedimentology, 23, doi:10.1111/j.1365-3091.2006.00812.x.

Fishbaugh, K., and J. Head (2000), North polar region of Mars: Topography of circumpolar deposits from Mars Orbiter Laser Altimeter (MOLA) data and evidence for asymmetric retreat of the polar cap, J. Geophys. Res., 105(E 9), 22, 455-22, 486.

Fishbaugh, K. E., and C. S. Hvidberg (2006), Martian north polar layered deposits stratigraphy: Implications for accumulation rates and flow, J. Geophys. Res., 111, E06012, doi:10.1029/2005JE002571.

Fishbaugh, K. E., S. Byrne, K. E. Herkenhoff, R. L. Kirk, C. Fortezzo, P. S. Russell, and A. McEwen (2010), Evaluating the meaning of "layer" in the Martian north polar layered deposits and the impact on the climate connection, Icarus, 205(1), 269-282, doi:10.1016/j.icarus.2009.04.011.

Fisher, D. A. (1993), If Martian ice caps flow: Ablation mechanisms and appearance, Icarus, 105(2), 501-511.

Frezzotti, M., S. Gandolfi, and S. Urbini (2002), Snow megadunes in Antarctica: Sedimentary structure and genesis, J. Geophys. Res., 107(D18), 4344, doi:10.1029/2001JD000673.

Gierasch, P., and C. Sagan (1971), A preliminary assessment of Martian wind regimes, Icarus, 14(3), 312-318, doi:10.1016/0019-1035(71)90003-0.

Grima, C., F. Costard, W. Kofman, B. Saint-Bézar, A. Servain, F. Rémy, J. Mouginot, A. Herique, and R. Seu (2011), Large asymmetric polar scarps on Planum Australe, Mars: Characterization and evolution, Icarus, 212(1), 96-109, doi:10.1016/j.icarus.2010.12.017.

Hager, W. H. (1992), Energy Dissipators and Hydraulic Jump, Springer, Dordrecht, The Netherlands.

Hand, B. M. (1974), Supercritical flow in density currents, J. Sediment. Res., 44(3), 637-648, doi:10.1306/74D72AB3-2B21-11D7-8648000102C1865D.

Hand, B. M., G. V. Middleton, and K. Skipper (1972), Antidune cross-stratification in a turbidite sequence, cloridorme formation, Gaspe, Quebec, Sedimentology, 18(1-2), 135-138, doi:10.1111/j.1365-3091.1972.tb00009.x.

Herkenhoff, K., and J. G. Plaut (2000), Surface ages and resurfacing rates of the polar layered deposits on Mars, Icarus, 144(2), 243-253, doi:10.1006/ icar.1999.6287.

Herkenhoff, K. E., S. Byrne, P. S. Russell, K. E. Fishbaugh, and A. S. McEwen (2007), Meter-scale morphology of the north polar region of Mars, Science, 317(5845), 1711-1715, doi:10.1126/science.1143544.

Holt, J. W., K. E. Fishbaugh, S. Byrne, S. Christian, K. Tanaka, P. S. Russell, K. E. Herkenhoff, A. Safaeinili, N. E. Putzig, and R. J. Phillips (2010), The construction of Chasma Boreale on Mars, Nature, 465(7297), 446-449, doi:10.1038/nature09050

Howard, A. D. (1978), Origin of the stepped topography of the Martian poles, Icarus, 34(3), 581-599.

Howard, A. D. (2000), The role of eolian processes in forming surface features of the Martian polar layered deposits, Icarus, 144(2), 267-288.

Howard, A. D., J. A. Cutts, and K. R. Blasius (1982), Stratigraphic relationships within Martian polar cap deposits, Icarus, 50(2-3), 161-215.

Hvidberg, C. S., K. E. Fishbaugh, M. Winstrup, A. Svensson, S. Byrne, and K. E. Herkenhoff (2012), Reading the climate record of the Martian polar layered deposits, Icarus, 221(1), 405-419, doi:10.1016/j. icarus.2012.08.009.

Ivanov, A. B., and D. O. Muhleman (2000), The role of sublimation for the formation of the northern ice cap: Results from the Mars Orbiter Laser Altimeter, Icarus, 144(2), 436-448, doi:10.1006/icar.1999.6304.

Kolb, E. J., and K. L. Tanaka (2001), Geologic history of the polar regions of Mars based on Mars Global Surveyor data II. Amazonian Period, Icarus, 154(1), 22-39.

Kostic, S., and G. Parker (2006), The response of turbidity currents to a canyon-fan transition: Internal hydraulic jumps and depositional signatures, J. Hydraul. Res., 44(5), 631, doi:10.1080/00221686.2006.9521713.

Kostic, S., O. Sequeiros, B. Spinewine, and G. Parker (2010), Cyclic steps: A phenomenon of supercritical shallow flow from the high mountains to the bottom of the ocean, J. Hydro-environ. Res., 3(4), 167-172.

Kuenen, P. H. (1951), Properties of turbidity currents of high density, Turbidity currents and the transportation of coarse sediments to deep water, 14-33.

Laskar, J., B. Levrard, and J. F. Mustard (2002), Orbital forcing of the Martian polar layered deposits, Nature, 419(6905), 375-377.

Lee, H. J., J. P. Syvitski, G. Parker, D. Orange, J. Locat, E. W. Hutton, and J. Imran (2002), Distinguishing sediment waves from slope failure deposits: Field examples, including the 'Humboldt slide', and modelling results, Mar. Geol., 192(1-3), 79-104.

Levrard, B., F. Forget, F. Montmessin, and J. Laskar (2007), Recent formation and evolution of northern Martian polar layered deposits as inferred from a Global Climate Model, J. Geophys. Res., 112, E06012, doi:10.1029/2006JE002772.

Lied, N. T. (1964), Stationary hydraulic jumps in a katabatic flow near Davis, Antarctica, 1961, Aust. Meteor. Mag, 47, 40-51.

Madeleine, J.-B., et al. (2012), Aphelion water-ice cloud mapping and property retrieval using the OMEGA imaging spectrometer onboard Mars Express, J. Geophys. Res., 117, E00J07, doi:10.1029/2011JE003940. 
Malin, M. C., et al. (1998), Early views of the Martian surface from the Mars Orbiter Camera of Mars Global Surveyor, Science, 279(5357), 1681-1685, doi:10.1126/science. 279.5357.1681.

Malin, M. C., et al. (2007), Context Camera Investigation on board the Mars Reconnaissance Orbiter, J. Geophys. Res., 112, E05S04, doi:10.1029/ 2006JE002808.

Massé, M., O. Bourgeois, S. Le Mouélic, C. Verpoorter, A. Spiga, and L. Le Deit (2012), Wide distribution and glacial origin of polar gypsum on Mars, Earth Planet. Sci. Lett., 317-318, 44-55, doi:10.1016/j.eps1.2011.11.035.

McEwen, A. S., E. M. Eliason, J. W. Bergstrom, N. T. Bridges, C. J. Hansen, W. A. Delamere, J. A. Grant, V. C. Gulick, K. E. Herkenhoff, and L. Keszthelyi (2007), Mars reconnaissance orbiter's high resolution imaging science experiment (HiRISE), J. Geophys. Res., 112, E05S02, doi:10.1029/2005JE002605.

Migeon, S., B. Savoye, and J. C. Faugeres (2000), Quaternary development of migrating sediment waves in the Var deep-sea fan: Distribution, growth pattern, and implication for levee evolution, Sediment. Geol., 133(3-4), 265-293.

Milkovich, S. M., and J. W. Head (2005), North polar cap of Mars: Polar layered deposit characterization and identification of a fundamental climate signal, J. Geophys. Res., 110, E01005, doi:10.1029/ 2004JE002349.

Milkovich, S. M., J. J. Plaut, A. Safaeinili, G. Picardi, R. Seu, and R. J. Phillips (2009), Stratigraphy of Promethei Lingula, south polar layered deposits, Mars, in radar and imaging data sets, J. Geophys. Res. 114, E03002, doi:10.1029/2008JE003162.

Mohrig, D., and J. G. Marr (2003), Constraining the efficiency of turbidity current generation from submarine debris flows and slides using laboratory experiments, Mar. Pet. Geol., 20(6-8), 883-899, doi:10.1016/j. marpetgeo.2003.03.002

Montmessin, F., F. Forget, P. Rannou, M. Cabane, and R. M. Haberle (2004), Origin and role of water ice clouds in the Martian water cycle as inferred from a general circulation model, J. Geophys. Res., 109, E10004, doi:10.1029/2004JE002284.

Murray, B. C., L. A. Soderblom, J. A. Cutts, R. P. Sharp, D. J. Milton, and R. B. Leighton (1972), Geological framework of the south polar region of Mars, Icarus, 17(2), 328-345.

Nakajima, T., M. Satoh, and Y. Okamura (1998), Channel-levee complexes, terminal deep-sea fan and sediment wave fields associated with the Toyama Deep-Sea channel system in the Japan Sea, Mar. Geol. 147(1-4), 25-41, doi:10.1016/S0025-3227(97)00137-0.

Neukum, G., and R. Jaumann (2004), HRSC: The High Resolution Stereo Camera of Mars Express, Mars Express: the Scientific Payload, 1240, 17-35.

Ng, F. S. L., and M. T. Zuber (2006), Patterning instability on the Mars polar ice caps, J. Geophys. Res., 111, E02005, doi:10.1029/2005JE002533.

Normark, W. R., G. R. Hess, D. A. V. Stow, and A. J. Bowen (1980), Sediment waves on the Monterey fan levee: A preliminary physical interpretation, Mar. Geol., 37(1-2), 1-18, doi:16/0025-3227(80)90009-2.

Ohtsu, I., Y. Yasuda, and H. Gotoh (2001), Hydraulic condition for undularjump formations, J. Hydraul. Res., 39(2), 203-209, doi:10.1080/ 00221680109499821 .

Parker, G. (1996), Some speculations on the relation between channel morphology and channel-scale flow structures, Proceedings, Coherent Flow in Open Channels, edited by P. J. Ashworth et al., John Wiley and Sons, Ltd.

Parker, G., and N. Izumi (2000), Purely erosional cyclic and solitary steps created by flow over a cohesive bed, J. Fluid Mech., 419, 203-238.

Parker, G., Y. Fukushima, and H. M. Pantin (1986), Self-accelerating turbidity currents, J. Fluid Mech., 171, 145-81.

Pathare, A. V., and D. A. Paige (2005), The effects of Martian orbital variations upon the sublimation and relaxation of north polar troughs and scarps, Icarus, 174(2), 419-443.

Pelletier, J. D. (2004), How do spiral troughs form on Mars?, Geology, 32(4), 365-367.

Pettré, P., and J. C. André (1991), Surface-pressure change through Loewe's phenomena and katabatic flow jumps: Study of two cases in Adelie Land, Antarctica, J. Atmos. Sci., 48, 557-571.

Pettré, P., C. Payan, and T. Paris (1993), Interaction of katabatic flow with local thermal effects in a coastal region of Adelie Land, east Antarctica, J. Geophys. Res., 98(D6), 10,429-10,440.

Phillips, R. J., M. T. Zuber, S. E. Smrekar, M. T. Mellon, J. W. Head, K. L. Tanaka, N. E. Putzig, S. M. Milkovich, B. A. Campbell, and J. J. Plaut (2008), Mars north polar deposits: Stratigraphy, age, and geodynamical response, Science, 320(5880), 1182.

Phillips, R. J., et al. (2011), Massive $\mathrm{CO}_{2}$ Ice deposits sequestered in the south polar layered deposits of Mars, Science, 332(6031), 838-841, doi:10.1126/science.1203091

Putzig, N. E., R. J. Phillips, B. A. Campbell, J. W. Holt, J. J. Plaut, L. M. Carter, A. F. Egan, F. Bernardini, A. Safaeinili, and R. Seu (2009), Subsurface structure of Planum Boreum from Mars Reconnaissance Orbiter Shallow Radar soundings, Icarus, 204(2), 443-457.
Reid, L. M. (1989), Channel incision by surface runoff in grassland catchments, University of Washington.

Rodriguez, J. A. P., and K. L. Tanaka (2011), Evidence for in-situ trough erosion in Planum Boreum, Mars, Fifth International Conference on Mars Polar Science and Exploration, 1323, 6015.

Seu, R., R. J. Phillips, D. Biccari, R. Orosei, A. Masdea, G. Picardi, A. Safaeinili, B. A. Campbell, J. J. Plaut, and L. Marinangeli (2007a), SHARAD sounding radar on the Mars Reconnaissance Orbiter, J. Geophys. Res., 112, E05S05, doi:10.1029/2006JE002745.

Seu, R., R. J. Phillips, G. Alberti, D. Biccari, F. Bonaventura, M. Bortone D. Calabrese, B. A. Campbell, M. Cartacci, and L. M. Carter (2007b), Accumulation and erosion of Mars' south polar layered deposits, Science, $317(5845), 1715$

Smith, I. B., and J. W. Holt (2010), Onset and migration of spiral troughs on Mars revealed by orbital radar, Nature, 465(7297), 450-453, doi:10.1038/ nature09049.

Smith, I. B., and J. W. Holt (2011), Implications for current and past atmospheric conditions of Mars from radar stratigraphic studies of spiral troughs in the north polar layered deposits, Fourth International workshop on the Mars Atmosphere: modelling and Observations.

Smith, D. E., M. T. Zuber, H. V. Frey, J. B. Garvin, J. W. Head D. O. Muhleman, G. H. Pettengill, R. J. Phillips, S. C. Solomon, and H. J. Zwally (2001), Mars Orbiter Laser Altimeter: Experiment summary after the first year of global mapping of Mars, J. Geophys. Res., 106(E10), 23,689-23,722, doi:10.1029/2000JE001364

Spiga, A. (2011), Elements of comparison between Martian and terrestrial mesoscale meteorological phenomena: Katabatic winds and boundary layer convection, Planet. Space Sci., 59(10), 915-922, doi:10.1016/j. pss.2010.04.025.

Spiga, A., and F. Forget (2009), A new model to simulate the Martian mesoscale and microscale atmospheric circulation: Validation and first results, J. Geophys. Res., 114, E02009, doi:10.1029/2008JE003242.

Spiga, A., F. Forget, J.-B. Madeleine, L. Montabone, S. R. Lewis, and E. Millour (2011), The impact of martian mesoscale winds on surface temperature and on the determination of thermal inertia, Icarus, 212 , 504-519, doi:10.1016/j.icarus.2011.02.001

Spinewine, B., O. E. Sequeiros, M. H. Garcia, R. T. Beaubouef, T. Sun, B. Savoye, and G. Parker (2009), Experiments on wedge-shaped deep sea sedimentary deposits in minibasins and/or on channel levees emplaced by turbidity currents. Part II. Morphodynamic evolution of the wedge and of the associated bedforms, J. Sediment. Res., 79(8), 608-628, doi:10.2110/jsr.2009.065

Squyres, S. W. (1979), The evolution of dust deposits in the Martian north polar region, Icarus, 40(2), 244-261.

Sun, T., and G. Parker (2005), Transportational cyclic steps created by flow over an erodible bed. Part 2. Theory and numerical simulation, J. Hydraul. Res., 43(5), 502-514.

Swithinbank, C., K. Brunk, and J. Sievers (1988), A glaciological map of Filchner-Ronne ice shelf, Antarctica, Ann. Glaciol., 11, 150-155.

Taki, K., and G. Parker (2005), Transportational cyclic steps created by flow over an erodible bed. Part 1. Experiments, J. Hydraul. Res., 43(5), 488-501, doi:10.1080/00221680509500147.

Toon, O., G. Ferry, R. P. Turco, J. Jordan, and J. Goodman (1989), Physical processes in polar stratospheric ice clouds, J. Geophys. Res., 94(D9), 11-359.

Turner, J. S. (1979), Buoyancy Effects in Fluids, 368 pp., Cambridge University Press, New York, NY.

Tyler, D. J., and J. R. Barnes (2005), A mesoscale model study of summertime atmospheric circulations in the north polar region of Mars, J. Geophys. Res., 110, E06007, doi:10.1029/2004JE002356.

Warner, N. H., and J. D. Farmer (2008), Importance of Aeolian processes in the origin of the north polar chasmata, Mars, Icarus, 196(2), 368-384, doi:10.1016/j.icarus.2007.08.043.

Weijermars, R. (1986), The polar spirals of Mars may be due to glacier surges deflected by Coriolis forces, Earth Planet. Sci. Lett. ISSN, $76(3-4), 227-240$

Whiteway, J. A., et al. (2009), Mars water-ice clouds and precipitation, Science, 325(5936), 68-70, doi:10.1126/science.1172344.

Winterwerp, J. C., W. T. Bakker, D. R. Mastbergen, and H. van Rossum (1992), Hyperconcentrated sand-water mixture flows over erodible bed, J. Hydraul. Eng., 119(11), 1508-1525.

Yokokawa, M., K. Okuno, A. Nakamura, T. Muto, Y. Miyata, H. Naruse, and G. Parker (2009), Aggradational cyclic steps: Sedimentary structures found in flume experiments, in Proceedings of the 33rd IAHR Biennial Congress, pp. 5547-5554.

Zammett, R. J., and A. C. Fowler (2007), Katabatic winds on ice sheets: A refinement of the Prandtl model, J. Atmos. Sci., 64(7), 2707-2716.

Zeng, Z., N. E. Putzig, H. Xie, S. J. Birnbaum, S. F. Ackely, and L. Liu (2008), Evidence of fractures in NPLD and their significance to the formation of Martian polar spiral troughs, Lunar and Planetary Institute Science Conference Abstracts, 39, 2179. 